Research Article

\title{
Influence of Blade Profiles on Plastic Centrifugal Pump Performance
}

\author{
Hui Zhang $(\mathbb{D}$, Lingfeng Tang, and Yongtao Zhao \\ School of Mechanical Engineering, Anhui Polytechnic University, Wuhu, Anhui 241000, China \\ Correspondence should be addressed to Hui Zhang; 2190110111@stu.ahpu.edu.cn
}

Received 9 October 2020; Revised 26 November 2020; Accepted 2 December 2020; Published 22 December 2020

Academic Editor: Jinyang Xu

Copyright (c) 2020 Hui Zhang et al. This is an open access article distributed under the Creative Commons Attribution License, which permits unrestricted use, distribution, and reproduction in any medium, provided the original work is properly cited.

\begin{abstract}
To study the influence of blade profiles of the plastic centrifugal pump on pump performance, the impeller blade profiles were designed and drawn by the single arc method, double arc method, logarithmic spiral method, and B-spline curve method, respectively, with the known structural parameters. The shape and size of four profiles were drawn, and two-dimensional models and three-dimensional models of four impellers and volute were completed, respectively. The impeller models were printed by 3D printing technology, and the performance experiments of the plastic centrifugal pump were carried out. The numerical simulation of the internal flow field was performed. From the contours of the velocity and pressure, the vapor volume fraction distribution, and fluid-structure interaction analysis of impellers, the impeller drawn by the logarithmic spiral method was better than others. The optimization of the logarithmic spiral method was completed. The impeller inlet and outlet diameters $\left(D_{1}\right.$ and $\left.D_{2}\right)$ and impeller inlet and outlet installation angles $\left(\beta_{1}\right.$ and $\left.\beta_{2}\right)$ were taken as control variables, and the total power loss and the minimum $\mathrm{NPSH}_{\mathrm{r}}$ of the pump were taken as the objective functions. The optimization results were that $D_{1}=58 \mathrm{~mm}$ and $D_{2}=162 \mathrm{~mm}$ and $\beta_{1}=17^{\circ}$ and $\beta_{2}=31^{\circ}$. The hydraulic efficiency was increased by $1.68 \%$.
\end{abstract}

\section{Introduction}

As a type of general machinery, centrifugal pumps are widely used such as in mechanical engineering, aerospace, and petrochemical industries [1-3]. The flow components of plastic centrifugal pumps are made of engineering plastic, with less manufacturing costs and better corrosion resistance. Plastic centrifugal pumps are suitable for most corrosive environments such as acid, alkali, and salt and can be applied to the transportation of corrosive materials in chemical and petroleum industries. However, it is well known that inevitable cavitation in centrifugal pumps will affect the pump performance and cause noise and vibrations [4-10].

The impeller is the core part of the centrifugal pump, and the impeller blade profile plays a vital role in the fluid flow which will directly impact the performance of centrifugal pumps. At present, there have been many studies on the influence of the impeller parameters on the flow characteristics of centrifugal pumps [11-20]. Tao et al. [21] used the numerical method to study how the blade thickness influenced the flow characteristics in the impeller passages and volute casing. They concluded that the pressure pulsations increased at the leading edges but decreased at the trailing edges according to the increase in the blade thickness. However, their work was only helpful for the design of ceramic pumps. Tao et al. [22] studied the influence of blade leading-edge shape on the cavitation and concluded it delayed the inception cavitation and critical cavitation. Peng et al. [23] analyzed various blade outlet angles without changing other impeller parameters and concluded that if the blade outlet angle was increased, the flow separation and the axial vortex along the blade working surface would be more serious. However, their work was aimed at low specific speed submersible pumps. Yu-Qin and Ze-Wen [24] studied how different blade numbers influenced the flow-induced noise of the centrifugal pump based on the idea of acousticvibration coupling. They found that the 6-blade model pump was the optimal value. Han et al. [25] presented an impeller and volute shape optimization design method that improved 
the hydraulic performance of the pump. Zhang et al. and Wang et al. $[26,27]$ explored the effects of slotted blades on the performance of centrifugal pumps. Li et al. [28] studied the influence of the blade angle of a low specific speed plastic centrifugal pump on the pump performance. They applied the one-way fluid-structure interaction but did not take the impact of structural deformation on performance into consideration.

The blade profile directly affects the bending of the blade and has an important impact on the fluid flow in the impeller channel. Studying the impact of the blade profile on the performance of the centrifugal pumps is beneficial to improve the performance and efficiency of the centrifugal pumps. Hu et al. [29] designed an iterative method of double arc blade profile for drawing cylindrical blade profile which overcame the shortcomings of blade profile drawing methods. El-Gazzar and Hawash [30] used the splitting technique to change the shape of the impeller and concluded that the impeller blade split caused the uneven mass distribution around the impeller, which led to the imbalance of the impeller. Ming et al. [31] proposed a new variable-angle spiral equation that was complementary to the traditional variable-angle spiral equation by changing the blade placement angle function.

In existing research studies, the studies on blade profile are mainly focused on metal pumps and a single profile, while only a few pieces of research are on the performance of plastic centrifugal pumps. Moreover, there is no regularity between the various blade profiles and the performance parameters of centrifugal pumps. In this paper, four design methods of blade profiles, which are the single arc method, double arc method, logarithmic spiral method, and B-spline curve method, are proposed and the influence of four kinds of blade profile on plastic centrifugal pump performance is studied. The flow field simulation of pumps with various impellers is analyzed in detail.

\section{Design Methods of Blade Profiles}

2.1. Single Arc Method. Figure 1 shows the design principle of the single arc method. In Figure $1, D_{1}$ and $D_{2}$ are impeller inlet and outlet diameters, respectively, $\beta_{1}$ and $\beta_{2}$ are the impeller inlet and outlet installation angles, respectively, and $\operatorname{arc} A B$ is the blade profile.

Take a random point (point $A$ ) on the entrance circle $D_{1}$. Take point $A$ as the fixed point. Draw a line with a $\beta_{1}$ angle and a length of $\rho$ in the negative direction of the $x$-axis. Take point $E$ as the endpoint. Then, take point $E$ as the center and $\rho$ as the radius to make the arc intersect the inlet and outlet circles at $A$ and $B$. Therefore, the $\operatorname{arc} A B$ is the blade profile of the single arc method.

The radius of curvature of the single arc:

$$
\rho=\frac{R_{2}^{2}-R_{1}^{2}}{2\left(R_{2} \cos \beta_{2}-R_{1} \cos \beta_{1}\right)},
$$

where $\rho=\mathrm{EA}$-radius of curvature of the single arc $(\mathrm{mm})$ and $R_{1}, R_{2}$-impeller inlet and outlet radii $(\mathrm{mm})$.

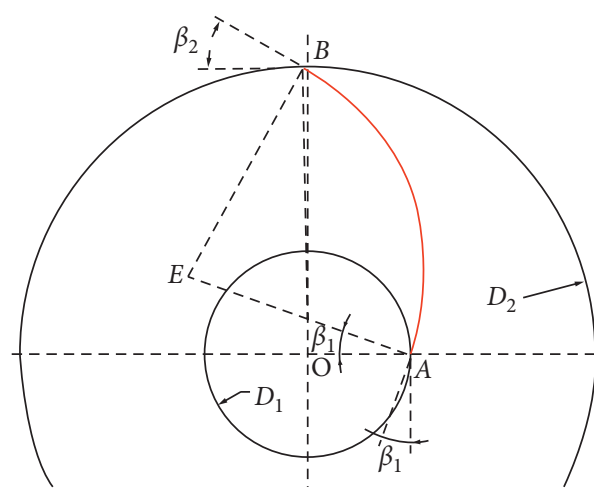

Figure 1: Blade profile of single arc method.

2.2. Double Arc Method. The principle of the double arc method is to find the radius of rotation according to the drawing method to determine the first arc and then calculate the value of the radius of rotation to determine the second arc according to the formula.

In Figure 2, $D_{1}$ and $D_{2}$ are impeller inlet and outlet diameters and $\beta_{1}$ and $\beta_{2}$ are the impeller inlet and outlet installation angles. Take $D_{1}$ as the diameter to make a circle and divide the circle into equal parts according to the number of blades $Z$. The equal points are $A_{1}, A_{2}, A_{3}, A_{4}, A_{5}$, and $A_{6}$. Take the diameter $\delta=D_{1} \sin \beta_{1}$ as the concentric circle with the diameter $D_{1}$. Make tangent lines $A_{1} E_{1}, A_{2} E_{2}$, $A_{3} E_{3}, A_{4} E_{4}, A_{5} E_{5}$, and $A_{6} E_{6}$ from each equal point to the circle of diameter $\delta$. Take $E_{1}$ as the center of the circle $\left(\angle \mathrm{E}_{1} \mathrm{~A}_{1} \mathrm{O}=\beta_{1}\right)$ and $E_{1} A_{1}$ as the radius to make an arc, which intersects the auxiliary circle (point $F$ ); then, the $\operatorname{arc} F A_{1}$ is the first profile of the blade. The second arc needs to meet three conditions which determine the position of point $P$. Three conditions are that (1) $F, E_{1}$, and $M$ points are collinear; (2) $\angle \mathrm{OPM}=\beta_{2}$; and (3) $\mathrm{PM}=\mathrm{MF}=\rho$.

The value of $\rho$ is

$$
\rho=\frac{1}{2} \frac{R_{2}^{2}-R_{f}^{2}}{R_{2} \cos \beta_{2}-R_{f} \cos \beta_{f}},
$$

where $\rho$-radius of rotation of the second $\operatorname{arc}(\mathrm{mm})$; $R_{f}$-radius of rotation of the point $F(\mathrm{~mm})$; and $\beta_{f}$-blade angle of point $F\left(^{\circ}\right)$.

After the position of point $P$ is determined, the center point $M$ can be determined and the second arc can be determined according to $\rho$.

2.3. Logarithmic Spiral Method. After determining the impeller inlet and outlet installation angles and the impeller inlet and out diameters, the blade wrap angle has a larger value range. Therefore, the advantage of the logarithmic spiral method in the shape of the cylindrical impeller's blade is also more prominent. Design and draw the impeller blade profile according to the equivariant angle spiral, and its design principle of the profile is shown in Figure 3.

In Figure 3, $\beta$ is impeller installation angle $\left(^{\circ}\right) ; \beta_{1}$ and $\beta_{2}$ are impeller inlet and outlet installation angles $\left({ }^{\circ}\right) ; D_{1}$ and $D_{2}$ 


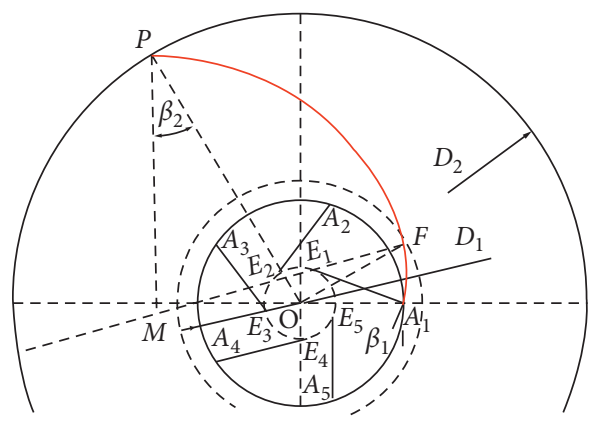

Figure 2: Blade profile of double arc method.

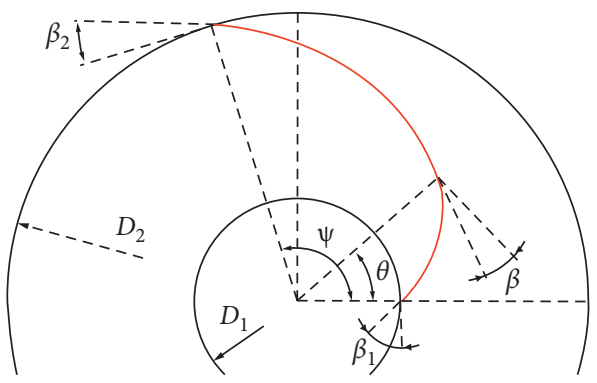

FIGURE 3: Blade profile of logarithmic spiral method.

are the impeller inlet and outlet diameters (mm); and $\theta$ is the variation of wrap angle $\psi\left({ }^{\circ}\right)$.

When $\beta_{1} \neq \beta_{2}$, the change law of $\beta$ is

$$
\beta=\left(\beta_{2}-\beta_{1}\right) \cdot \frac{\theta}{\varphi}+\beta_{1} \text {. }
$$

Profile equation:

$$
r=r_{1}\left[\frac{\cos \beta_{1}}{\cos \left[\left(\beta_{2}-\beta_{1} / \varphi\right) \theta+\beta_{1}\right]}\right]^{\left(\Psi / \beta_{2}-\beta_{1}\right)} .
$$

Wrap angle:

$$
\varphi=\frac{\left(\beta_{2}-\beta_{1}\right) \ln \left(r_{2} / r_{1}\right)}{\ln \left(\cos \beta_{1} / \cos \beta_{2}\right)} .
$$

Substitute $\beta_{1}=20, \beta_{2}=30, D_{1}=58 \mathrm{~mm}$, and $D_{2}=162 \mathrm{~mm}$ into the program written by MATLAB software, and the resulting blade profile is shown in Figure 4(a).

2.4. B-Spline Curve Method. Use 5-point (or 4-point) Bezier curve to fit the studied impeller profile, which eliminates the inconvenience of curve adjustment caused by traditional cubic polynomial fitting and makes the design of blade profile simpler, smoother, and easier to control. Determine the coordinates of the control points first. According to the Bezier equation, $n=4$,

$$
\begin{aligned}
P_{(t)}= & (1-t)^{4} P_{0}+4 t(1-t)^{3} P_{1}+6 t^{2}(1-t)^{2} P_{2} \\
& +4 t^{3}(1-t) P_{3}+t^{4} P_{4} .
\end{aligned}
$$

The coordinate of any point $P\left(x_{p}, y_{p}\right)$ on the Bezier curve

$$
\begin{aligned}
x_{p}= & (1-t)^{4} x_{0}+4 t(1-t)^{3} x_{1}+6 t^{2}(1-t)^{2} x_{2} \\
& +4 t^{3}(1-t) x_{3}+t^{4} x_{4}, \\
y_{p}= & (1-t)^{4} y_{0}+4 t(1-t)^{3} y_{1}+6 t^{2}(1-t)^{2} y_{2} \\
& +4 t^{3}(1-t) y_{3}+t^{4} y_{4} .
\end{aligned}
$$

Figure 5 shows the design principle of the B-spline curve method. In Figure 5, the impeller inlet and outlet installation angles $\beta_{1}$ and $\beta_{2}$ and the impeller inlet and outlet diameters $D_{1}$ and $D_{2}$ are the known parameters.

Substitute $\beta_{1}=20, \beta_{2}=30, D_{1}=58 \mathrm{~mm}, D_{2}=162 \mathrm{~mm}$, and $\psi=88.3$ into the calculation and obtain $P_{0}(0,29), P_{1}$ $(-26.32,38.58), P_{2}(60.87,12.77), P_{3}(-66.79,25.49)$, and $P_{4}(-81,2.83)$. From the obtained coordinates of $P_{0}, P_{1}, P_{2}$, $P_{3}$, and $P_{4}$, the designed blade profile can be drawn by MATLAB software, as shown in Figure 4(b).

\section{Numerical Simulation Method}

3.1. Computation Model. Take the plastic centrifugal pump designed by a certain unit as an example, and its main design parameters are shown in Table 1 . According to the known structural parameters of a plastic centrifugal pump, the impeller blade profiles were designed and drawn by the single arc method, double arc method, logarithmic spiral method, and B-spline curve method, respectively.

Figure 6 shows a two-dimensional diagram of the impeller. According to the parameters of the impeller in Figure 6, the UG software is used to design the three-dimensional model of the impeller. The three-dimensional models of the impeller with four profile design methods are shown in Figure 7.

Figure 8 shows a two-dimensional diagram of the volute. According to the parameters of the volute in Figure 8, the UG software is used to design the three-dimensional model of the volute. The three-dimensional model of the volute is shown in Figure 9.

3.2. Meshing. According to the above completed three-dimensional models, ANSYS-ICEM software is employed to utilized to mesh the computational domains. When we mesh the models, the actual grid cannot reach the ideal shape. If the grid deforms or deformation exceeds a certain limit, the accuracy of the calculation results will change accordingly. Therefore, in the initial division of the grid, it is necessary to use appropriate measures to control or measure the quality of the grid and try to achieve the best grid. The final determination of the number of grid cells in each part of the computational domains is shown in Table 2.

The final meshing is shown in Figure 10.

3.3. Computational Setup. Numerical calculations were performed in FLUENT software. The turbulence model was a k-epsilon (equation (2)) turbulence model. The computational impeller domain was set to a rotational domain. All other computational domains were set to static.

The boundary conditions were set to velocity inlet and outflow. The relevant setting parameters were set by default. The reference pressure was set to standard atmospheric 


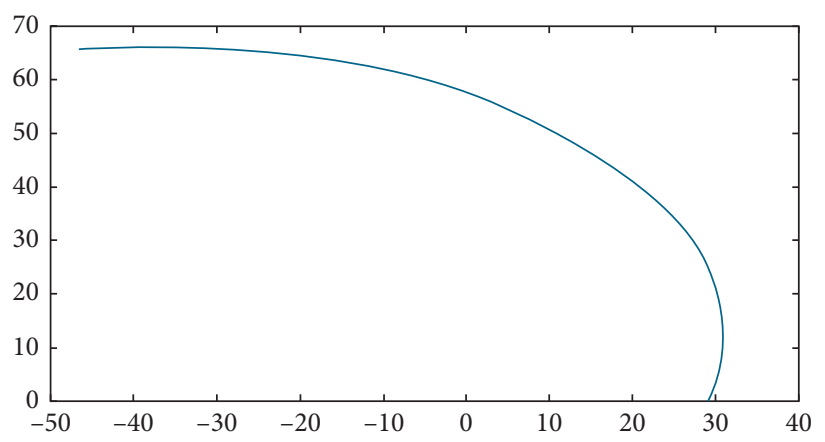

(a)

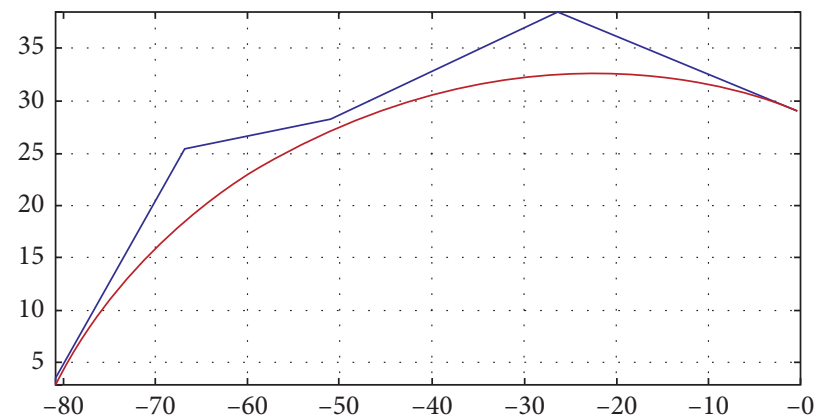

(b)

Figure 4: Blade profiles drawn by MATLAB software. (a) Logarithmic spiral method. (b) B-spline curve method.

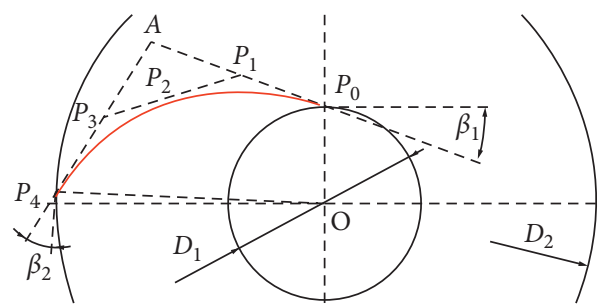

FIGURE 5: Blade profile of B-spline curve method.

Table 1: Design parameters of plastic centrifugal pump.

\begin{tabular}{|c|c|c|c|}
\hline \multicolumn{2}{|c|}{ Performance parameters } & \multicolumn{2}{|c|}{ Geometrical dimension } \\
\hline $\mathrm{Q}\left(\mathrm{m}^{3} / \mathrm{h}\right)$ & 20 & Impeller inlet diameter $(\mathrm{mm})$ & 58 \\
\hline $\mathrm{H}(\mathrm{m})$ & 30 & Impeller outlet diameter $(\mathrm{mm})$ & 162 \\
\hline$n(\mathrm{r} / \mathrm{min})$ & 2900 & Impeller inlet width (mm) & 23 \\
\hline$n_{\mathrm{s}}$ & 60.871 & Impeller outlet width (mm) & 10 \\
\hline$P_{t}(\mathrm{~kW})$ & 5.5 & Impeller inlet installation angle $\left({ }^{\circ}\right)$ & 20 \\
\hline $\mathrm{NPSH}_{\mathrm{a}}(\mathrm{m})$ & 4 & Impeller outlet installation angle $\left({ }^{\circ}\right)$ & 30 \\
\hline Volute width $(\mathrm{mm})$ & 33 & Base circle diameter of volute $(\mathrm{mm})$ & 175 \\
\hline
\end{tabular}
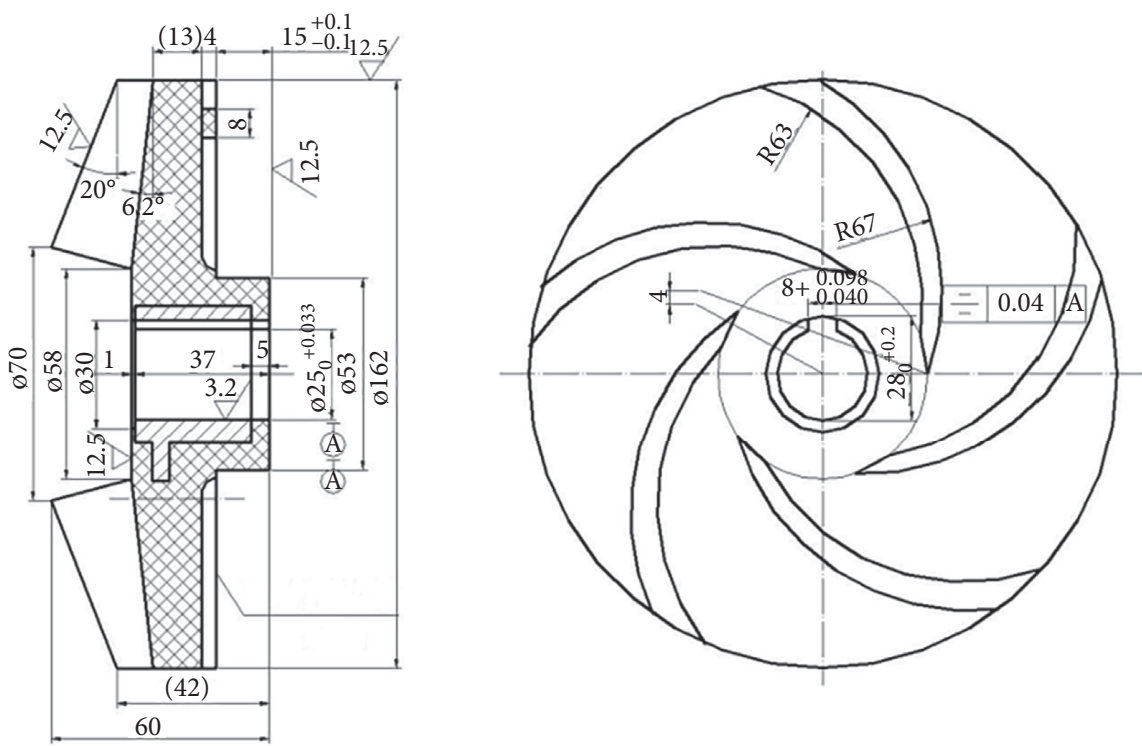

Figure 6: Two-dimensional diagram of the impeller. 


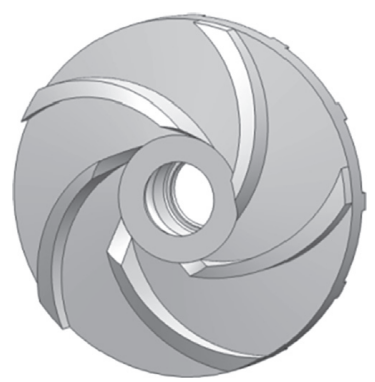

(a)

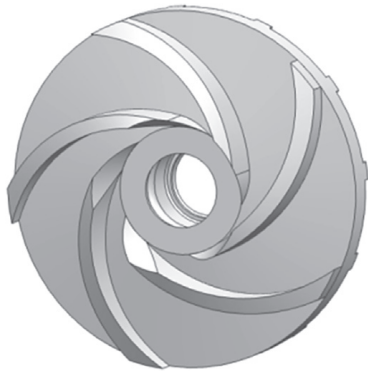

(b)

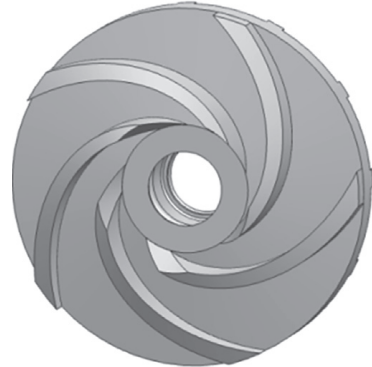

(c)

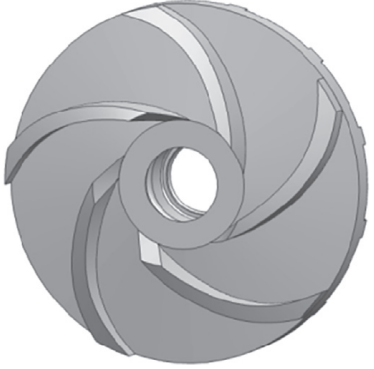

(d)

FIGURE 7: Models of impellers drawn by four profile design methods. (a) Single arc. (b) Double arc. (c) Logarithmic spiral. (d) B-spline curve.
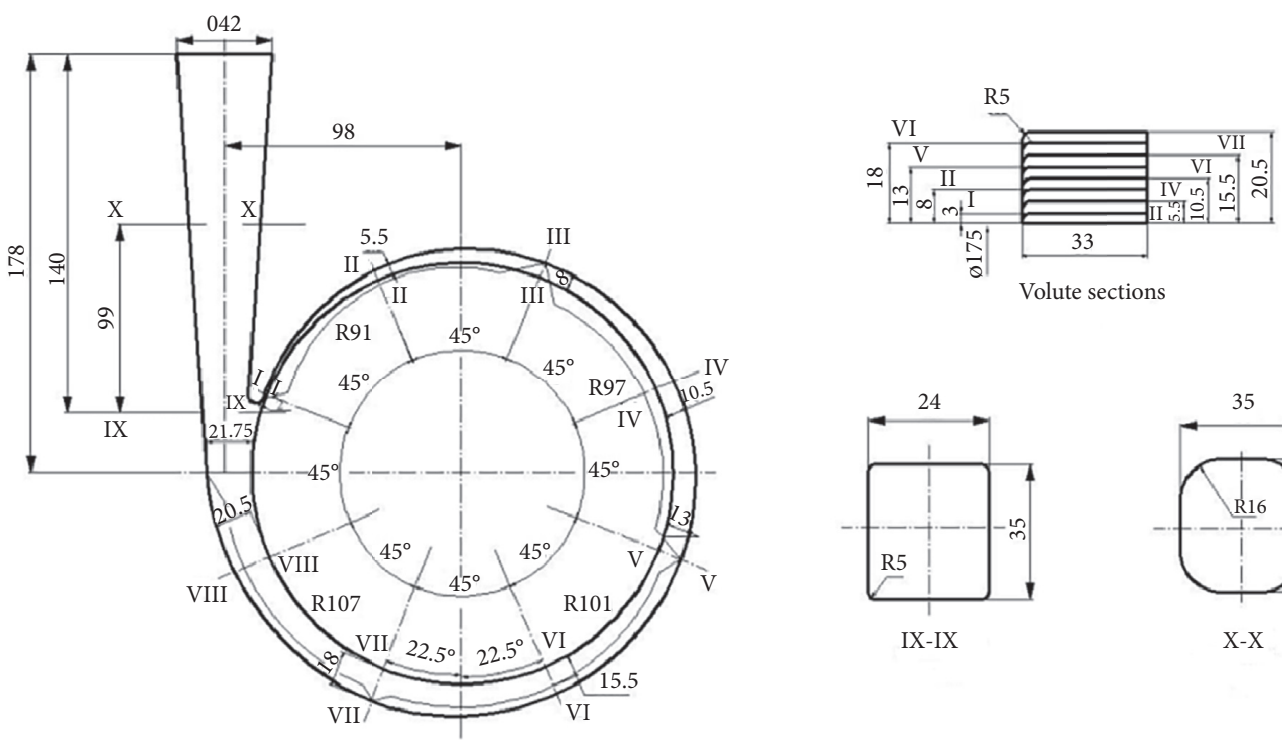

FiguRE 8: Two-dimensional diagram of the volute.

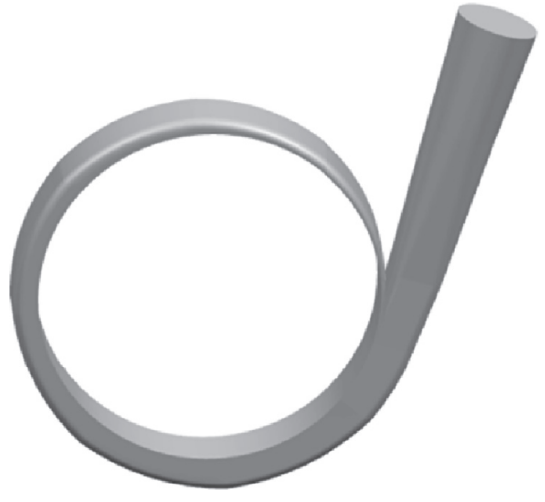

Figure 9: Model of volute.

TABLE 2: The number of grid cells.

\begin{tabular}{lcccc}
\hline $\begin{array}{l}\text { Computational } \\
\text { domains }\end{array}$ & $\begin{array}{c}\text { Inlet } \\
\text { extension }\end{array}$ & Impeller & Volute & $\begin{array}{c}\text { Outlet } \\
\text { extension }\end{array}$ \\
\hline $\begin{array}{l}\text { The number of grid } \\
\text { cells }\end{array}$ & 581102 & 397526 & 393266 & 1502055 \\
\hline
\end{tabular}

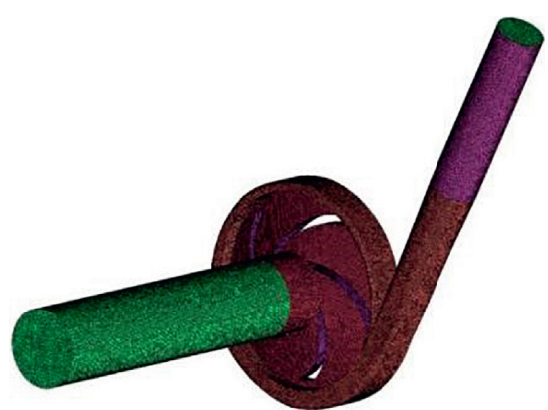

FIgURE 10: Meshing.

pressure. The wall surface was placed under a non-slip boundary condition, and a standard wall surface function was applied. The calculation method was SIMPLEC. The convergence accuracy was set to $10^{-4}$.

\section{Test Verification}

4.1. 3D Printing of Plastic Centrifugal Pump Impellers. UTR9000 material was used for 3D printing of impellers, which was an ABS-like stereo light modeling resin with 
accurate and durable characteristics. The durability of components made of UTR9000 resin was more than 6.5 months. According to the three-dimensional models of the impellers drawn by four profile design methods (Figure 6), the impeller models printed by $3 \mathrm{D}$ printing technology are shown in Figure 11.

4.2. Performance Tests of Plastic Centrifugal Pump. Figure 12 shows the pump performance test bench, which mainly included a motor and a flow control valve.

The pump test system (electrical measurement method) V8.97 software on the data acquisition platform was used to collect data at each operating point by adjusting the flow control valve. The pump performance experiments were performed on the impellers of the four types of profiles. The parameter settings before the experiment are shown in Table 3, and the collected data are shown in Tables 4-7.

4.3. Data Analysis. Figures 13 and 14 show the comparison of head and efficiency in performance experiments of four types of impellers. From the shut-off point to the maximum flow condition during the test, 13 flow condition points were selected to completely reflect the external characteristic variation curve. It can be seen that the efficiency of the logarithmic spiral method was better than that of the other three methods, and the efficiency of the single arc method was the worst.

\section{Analysis of Numerical Simulation Results}

5.1. Velocity in the Flow Field. Figure 15 shows the contours of the velocity of the four impellers, respectively. As shown in Figure 15, when the other parameters were consistent, the impellers drawn by four profile design methods had insufficient fluid flow, and the internal flow fields in the impellers drawn by the single arc method and B-spline curve method had obvious vortex. The internal flow fields in the impellers drawn by the double arc method and logarithmic spiral method were significantly better than those drawn by the B-spline curve method and single arc method.

5.2. Pressure in the Flow Field. Figure 16 shows the contours of the pressure of the four impellers, respectively. As shown in Figure 16, when the other parameters were consistent, the internal pressure trends of the impellers drawn by four design methods were correct, and the stratification was obvious. There was negative pressure near the impeller inlet in the flow fields of impellers drawn by the single arc method and B-spline method, while negative pressure did not occur in the other two flow fields of impellers. The maximum pressure values corresponding to the four methods were $437563 \mathrm{~Pa}, 441628 \mathrm{~Pa}, 438368 \mathrm{~Pa}$, and $435518 \mathrm{~Pa}$. The pressure fields in the impellers drawn by the double arc method and logarithmic spiral method were significantly better.
5.3. Cavitation in the Flow Field. Figure 17 shows the vapor volume fraction distribution in four impellers when $\mathrm{NPSH}_{\mathrm{r}}$ was $1 \mathrm{~m}$. As shown in Figure 17, when $\mathrm{NPSH}_{\mathrm{r}}$ was $1 \mathrm{~m}$, the bubbles almost filled the entire impellers. The vapor volume fractions of the impellers drawn by the double arc method and logarithmic spiral method were 0.9455 and 0.9449 , which were significantly lower than those in the other two impellers. The impeller drawn by the single arc method had the largest value.

Figure 18 shows the vapor volume fraction distribution in four impellers when $\mathrm{NPSH}_{\mathrm{r}}$ was $2 \mathrm{~m}$. As shown in Figure 18, when $\mathrm{NPSH}_{\mathrm{r}}$ was $2 \mathrm{~m}$, bubbles filled one third of the entire impellers. The vapor volume fractions of the impellers drawn by the double arc method and logarithmic spiral method were 0.861 and 0.8174 , which were significantly lower than those in the other two impellers. The impeller drawn by the B-spline curve had the largest value.

In summary, when $\mathrm{NPSH}_{\mathrm{r}}=1 \mathrm{~m}$ and $2 \mathrm{~m}$, the impeller drawn by the logarithmic spiral method is significantly better than the other three impellers, which means that the logarithmic spiral method is the best design method.

5.4. Analysis of Efficiency. According to the above conclusion, CFD-Post software was used to calculate the performance parameters of the four profiles, as shown in Table 8 . From Table 8, it can be concluded that the impeller of the logarithmic spiral method was the optimal impeller under the design condition.

\subsection{Analysis of Blade Profiles Based on Fluid-Structure} Interaction. The purpose of fluid-structure interaction was to find how the flow field influenced the impeller, which was mainly reflected in the deformation of the impeller caused by the fluid, and the force on the impeller. ANSYS-CFX software was used to complete the fluid-structure interaction analysis.

Figure 19 shows the total deformation of the impellers drawn by four profile design methods under the same working condition. As a whole, the total deformation distribution of the four impellers was symmetrical and stratified obviously. The deformation of the impellers increased continuously with the increase of the radius, the maximum deformation occurred at the edge of the impellers, and the minimum deformation occurred at the inlet of the impellers.

The maximum total deformation of the impellers drawn by four profile design methods was $0.61503 \mathrm{~mm}$, $0.58614 \mathrm{~mm}, 0.57442 \mathrm{~mm}$, and $0.61609 \mathrm{~mm}$, respectively. The following can be concluded for total deformation: B-spline curve method $>$ single arc method $>$ double arc method $>$ logarithmic spiral method.

Figure 20 shows the equivalent stress of the impellers drawn by four profile design methods under the same working conditions. As a whole, the impeller stress was mainly concentrated on the blade root, where the equivalent stress was significantly greater than that in other areas. Therefore, compared to other positions, the blade root near the impeller inlet was more prone to stress concentration. 


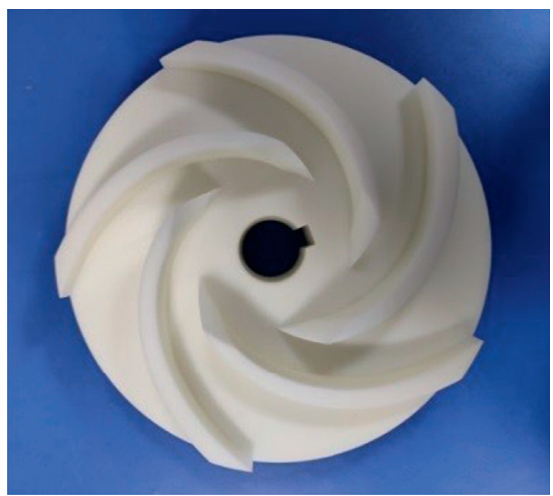

(a)

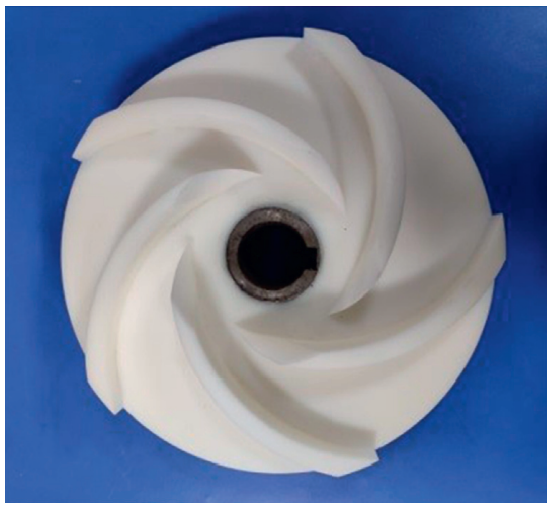

(c)

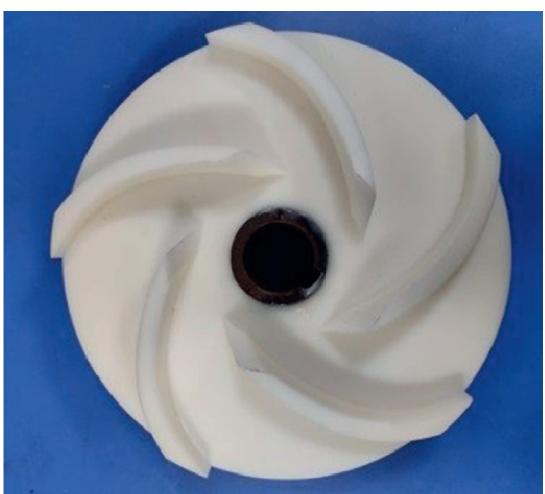

(b)

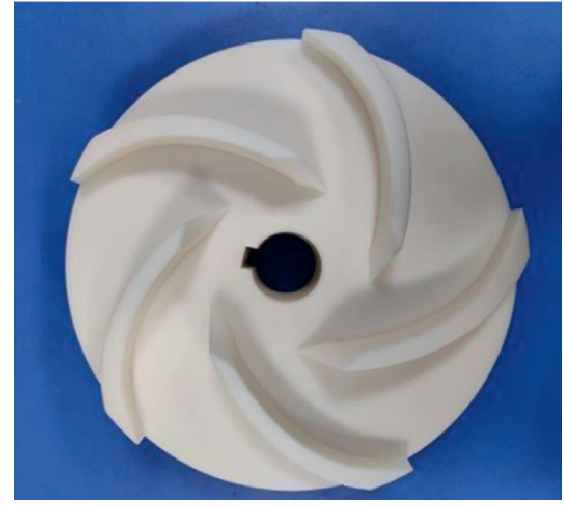

(d)

Figure 11: 3D printing of impellers. (a) Single arc. (b) Double arc. (c) Logarithmic spiral. (d) B-spline curve.

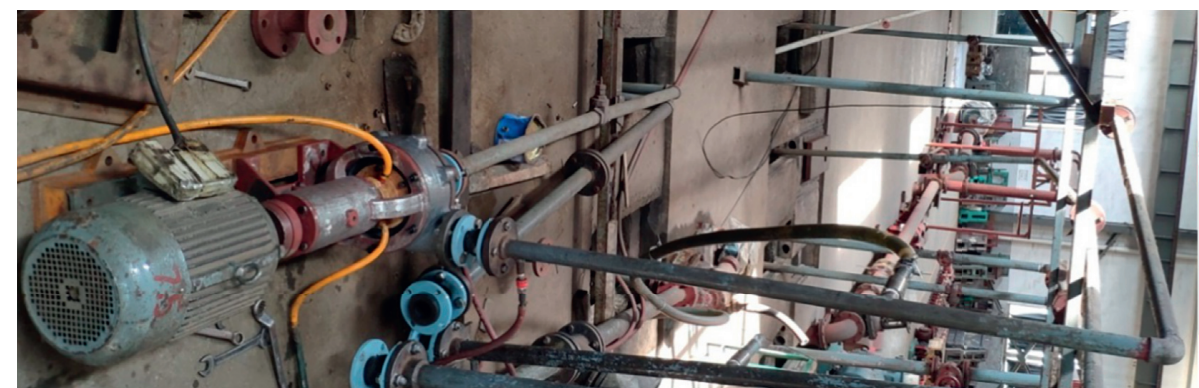

Figure 12: Pump performance test bench.

TABLE 3: Parameter settings of pump performance experiment.

\begin{tabular}{lccccc}
\hline Product number & Fluid density $\left(\mathrm{kg} / \mathrm{m}^{3}\right)$ & Fluid viscosity $(\mathrm{CST})$ & Meter factor $(\mathrm{f} / \mathrm{1})$ & Inlet diameter $(\mathrm{m})$ & Outlet diameter $(\mathrm{m})$ \\
\hline 50UHB15-32 & Water & Water & 79.89 & 0.05 & 0.032 \\
\hline
\end{tabular}

TABLE 4: Performance experiment of single arc method.

Measured value

\begin{tabular}{|c|c|c|c|c|c|c|c|c|c|}
\hline & & \\
\hline & $\begin{array}{c}\text { Inlet pressure } \\
(\mathrm{kPa})\end{array}$ & $\begin{array}{c}\text { Outlet pressure } \\
(\mathrm{kPa})\end{array}$ & $\begin{array}{c}Q \\
\left(\mathrm{~m}^{3} / \mathrm{h}\right) \\
\end{array}$ & $\begin{array}{c}n \\
(\mathrm{r} / \mathrm{min})\end{array}$ & $\begin{array}{c}P_{\text {in }} \\
(\mathrm{kW})\end{array}$ & $\begin{array}{c}Q \\
\left(\mathrm{~m}^{3} / \mathrm{h}\right) \\
\end{array}$ & $\begin{array}{c}H \\
(\mathrm{~m})\end{array}$ & $\begin{array}{c}P_{\text {in }} \\
(\mathrm{kW})\end{array}$ & $\begin{array}{c}\eta \\
(\%)\end{array}$ \\
\hline 1 & -70.00 & 170.00 & 20.95 & 2998.60 & 5.85 & 20.26 & 25.72 & 5.29 & 26.83 \\
\hline 2 & -80.00 & 220.00 & 19.93 & 3001.44 & 5.83 & 19.26 & 31.19 & 5.26 & 31.11 \\
\hline 3 & -70.00 & 240.00 & 18.92 & 3002.21 & 5.81 & 18.28 & 31.94 & 5.24 & 30.37 \\
\hline
\end{tabular}


TABle 4: Continued.

\begin{tabular}{|c|c|c|c|c|c|c|c|c|c|}
\hline & \multicolumn{4}{|c|}{ Measured value } & & \multicolumn{4}{|c|}{$n=2900(\mathrm{r} / \mathrm{min})$} \\
\hline & $\begin{array}{l}\text { Inlet pressure } \\
\qquad(\mathrm{kPa})\end{array}$ & $\begin{array}{l}\text { Outlet pressure } \\
\qquad(\mathrm{kPa})\end{array}$ & $\begin{array}{c}Q \\
\left(\mathrm{~m}^{3} / \mathrm{h}\right)\end{array}$ & $\begin{array}{c}n \\
(\mathrm{r} / \mathrm{min})\end{array}$ & $\begin{array}{c}P_{\text {in }} \\
(\mathrm{kW})\end{array}$ & $\begin{array}{c}Q \\
\left(\mathrm{~m}^{3} / \mathrm{h}\right)\end{array}$ & $\begin{array}{c}H \\
(\mathrm{~m})\end{array}$ & $\begin{array}{c}P_{\text {in }} \\
(\mathrm{kW})\end{array}$ & $\begin{array}{c}\eta \\
(\%)\end{array}$ \\
\hline 4 & -60.00 & 260.00 & 16.35 & 3001.81 & 5.56 & 15.80 & 32.47 & 5.01 & 27.87 \\
\hline 5 & -50.00 & 280.00 & 14.86 & 3001.81 & 5.37 & 14.36 & 33.21 & 4.84 & 26.82 \\
\hline 6 & -40.00 & 300.00 & 12.93 & 3002.06 & 5.12 & 12.49 & 33.90 & 4.62 & 24.99 \\
\hline 7 & -30.00 & 310.00 & 10.91 & 3002.36 & 4.96 & 10.54 & 33.66 & 4.47 & 21.62 \\
\hline 8 & -20.00 & 330.00 & 8.28 & 3001.63 & 4.68 & 8.00 & 34.39 & 4.22 & 17.76 \\
\hline 9 & -20.00 & 340.00 & 6.33 & 3001.54 & 4.53 & 6.12 & 35.21 & 4.09 & 14.36 \\
\hline 10 & -10.00 & 350.00 & 2.44 & 3001.34 & 4.26 & 2.36 & 35.06 & 3.84 & 5.86 \\
\hline 11 & -10.00 & 360.00 & 1.49 & 3001.16 & 4.22 & 1.44 & 36.00 & 3.81 & 3.71 \\
\hline 12 & -10.00 & 360.00 & 0.21 & 3000.81 & 4.15 & 0.20 & 35.99 & 3.75 & 0.53 \\
\hline 13 & 0.00 & 380.00 & 0.00 & 3000.90 & 4.03 & 0.00 & 36.94 & 3.64 & 0.00 \\
\hline
\end{tabular}

Table 5: Performance experiment of double arc method.

\begin{tabular}{|c|c|c|c|c|c|c|c|c|c|}
\hline & \multicolumn{4}{|c|}{ Measured value } & & \multicolumn{4}{|c|}{$n=2900(\mathrm{r} / \mathrm{min})$} \\
\hline & $\begin{array}{c}\text { Inlet pressure } \\
(\mathrm{kPa})\end{array}$ & $\begin{array}{c}\text { Outlet pressure } \\
(\mathrm{kPa})\end{array}$ & $\begin{array}{c}Q \\
\left(\mathrm{~m}^{3} / \mathrm{h}\right) \\
\end{array}$ & $\begin{array}{c}n \\
(\mathrm{r} / \mathrm{min}) \\
\end{array}$ & $\begin{array}{c}P_{\text {in }} \\
(\mathrm{kW})\end{array}$ & $\begin{array}{c}Q \\
\left(\mathrm{~m}^{3} / \mathrm{h}\right) \\
\end{array}$ & $\begin{array}{c}H \\
(\mathrm{~m})\end{array}$ & $\begin{array}{c}P_{\text {in }} \\
(\mathrm{kW})\end{array}$ & $\begin{array}{c}\eta \\
(\%) \\
\end{array}$ \\
\hline 1 & -80.00 & 190.00 & 21.19 & 3000.59 & 5.47 & 20.48 & 28.60 & 4.94 & 32.31 \\
\hline 2 & -80.00 & 220.00 & 19.98 & 2998.58 & 5.33 & 19.32 & 31.26 & 4.82 & 34.13 \\
\hline 3 & -70.00 & 240.00 & 18.09 & 2997.92 & 5.21 & 17.50 & 31.89 & 4.72 & 32.23 \\
\hline 4 & -70.00 & 250.00 & 16.89 & 2998.15 & 5.18 & 16.34 & 32.64 & 4.69 & 30.98 \\
\hline 5 & -50.00 & 280.00 & 14.25 & 2998.20 & 5.01 & 13.78 & 33.20 & 4.53 & 27.50 \\
\hline 6 & -40.00 & 290.00 & 12.63 & 2998.18 & 4.82 & 12.22 & 33.00 & 4.36 & 25.17 \\
\hline 7 & -30.00 & 310.00 & 10.85 & 2997.94 & 4.60 & 10.50 & 33.76 & 4.16 & 23.18 \\
\hline 8 & -20.00 & 330.00 & 8.56 & 2998.14 & 4.44 & 8.28 & 34.50 & 4.02 & 19.36 \\
\hline 9 & -20.00 & 340.00 & 6.70 & 2998.48 & 4.32 & 6.48 & 35.31 & 3.91 & 15.95 \\
\hline 10 & -10.00 & 350.00 & 4.83 & 2998.58 & 4.20 & 4.67 & 35.20 & 3.80 & 11.79 \\
\hline 11 & -10.00 & 360.00 & 2.06 & 2998.72 & 3.99 & 1.99 & 36.06 & 3.61 & 5.42 \\
\hline 12 & -10.00 & 370.00 & 0.24 & 2999.02 & 3.82 & 0.23 & 36.99 & 3.45 & 0.68 \\
\hline 13 & -10.00 & 380.00 & 0.00 & 2999.52 & 3.71 & 0.00 & 37.93 & 3.35 & 0.00 \\
\hline
\end{tabular}

Table 6: Performance experiment of logarithmic spiral method.

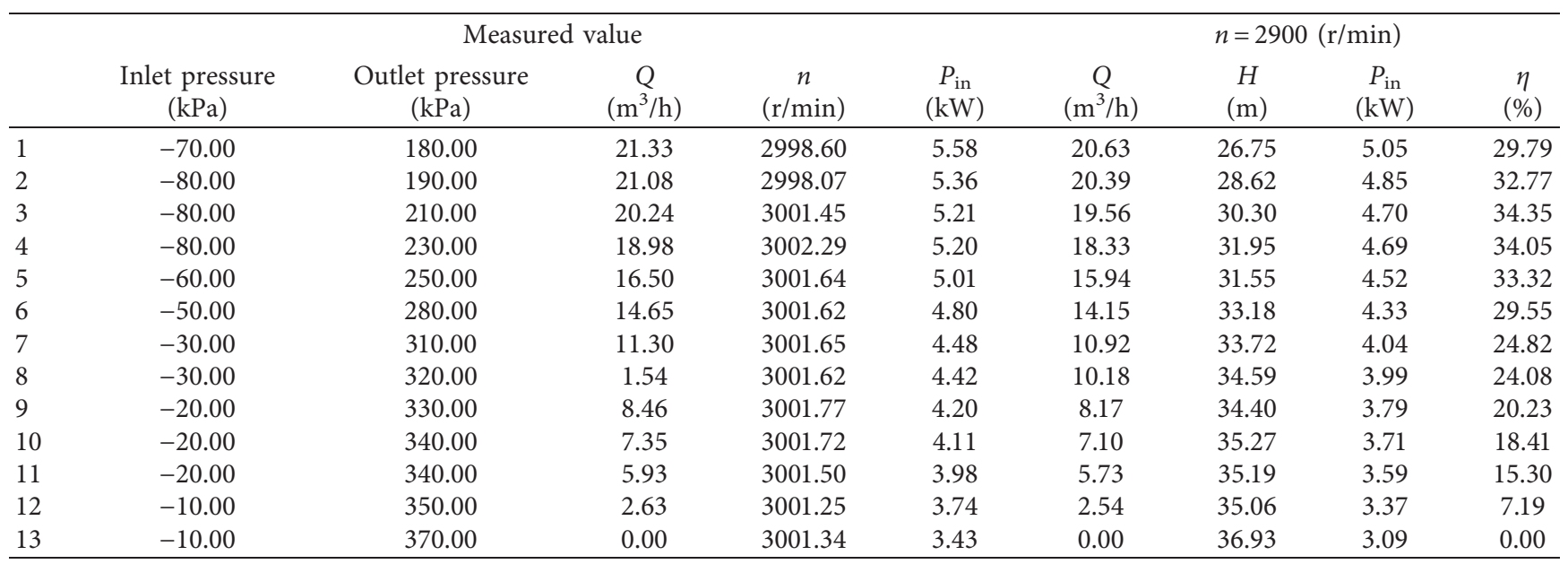

The maximum equivalent stress of the impellers drawn by four profiles was $41.357 \mathrm{MPa}, 41.43 \mathrm{MPa}, 40.909 \mathrm{MPa}$, and $44.891 \mathrm{MPa}$, respectively. The following can be concluded for equivalent stress: B-spline curve method$>$ double arc method $>$ single arc method $>$ logarithmic spiral method. 
TABle 7: Performance experiment of B-spline curve method.

\begin{tabular}{|c|c|c|c|c|c|c|c|c|c|}
\hline & \multicolumn{4}{|c|}{ Measured value } & & \multicolumn{4}{|c|}{$n=2900(\mathrm{r} / \mathrm{min})$} \\
\hline & $\begin{array}{l}\text { Inlet pressure } \\
\qquad(\mathrm{kPa})\end{array}$ & $\begin{array}{l}\text { Outlet pressure } \\
\qquad(\mathrm{kPa})\end{array}$ & $\begin{array}{c}Q \\
\left(\mathrm{~m}^{3} / \mathrm{h}\right)\end{array}$ & $\begin{array}{c}n \\
(\mathrm{r} / \mathrm{min})\end{array}$ & $\begin{array}{c}P_{\text {in }} \\
(\mathrm{kW})\end{array}$ & $\begin{array}{c}Q \\
\left(\mathrm{~m}^{3} / \mathrm{h}\right)\end{array}$ & $\begin{array}{c}H \\
(\mathrm{~m})\end{array}$ & $\begin{array}{c}P_{\text {in }} \\
(\mathrm{kW})\end{array}$ & $\begin{array}{c}\eta \\
(\%)\end{array}$ \\
\hline 1 & -80.00 & 180.00 & 21.27 & 2998.15 & 5.40 & 20.57 & 27.70 & 4.89 & 31.77 \\
\hline 2 & -80.00 & 220.00 & 20.05 & 3001.80 & 5.31 & 19.37 & 31.21 & 4.79 & 34.39 \\
\hline 3 & -80.00 & 240.00 & 17.69 & 3001.60 & 5.13 & 17.09 & 32.69 & 4.63 & 32.90 \\
\hline 4 & -80.00 & 250.00 & 16.65 & 3001.51 & 5.03 & 16.09 & 33.48 & 4.54 & 32.34 \\
\hline 5 & -60.00 & 280.00 & 14.91 & 3001.36 & 4.81 & 14.41 & 34.17 & 4.34 & 30.91 \\
\hline 6 & -40.00 & 300.00 & 12.75 & 3001.13 & 4.60 & 12.32 & 33.90 & 4.15 & 27.41 \\
\hline 7 & -30.00 & 310.00 & 11.08 & 3000.93 & 4.44 & 10.71 & 33.71 & 4.01 & 24.54 \\
\hline 8 & -30.00 & 330.00 & 8.29 & 3000.63 & 4.26 & 8.01 & 35.37 & 3.85 & 20.07 \\
\hline 9 & -20.00 & 340.00 & 7.06 & 3000.61 & 4.17 & 6.82 & 35.28 & 3.76 & 17.42 \\
\hline 10 & -20.00 & 350.00 & 5.81 & 3000.56 & 4.05 & 5.62 & 36.16 & 3.66 & 15.13 \\
\hline 11 & -10.00 & 350.00 & 4.75 & 3000.45 & 3.92 & 4.59 & 35.16 & 3.54 & 12.42 \\
\hline 12 & -10.00 & 360.00 & 3.29 & 3000.55 & 3.82 & 3.18 & 36.05 & 3.45 & 9.05 \\
\hline 13 & -10.00 & 370.00 & 2.14 & 3000.56 & 3.72 & 2.07 & 36.97 & 3.36 & 6.20 \\
\hline
\end{tabular}

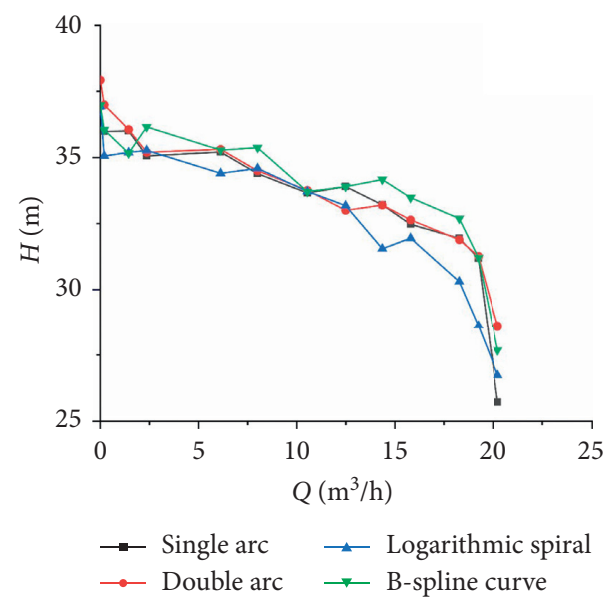

FIgURE 13: $Q-H$ curves of four profiles.

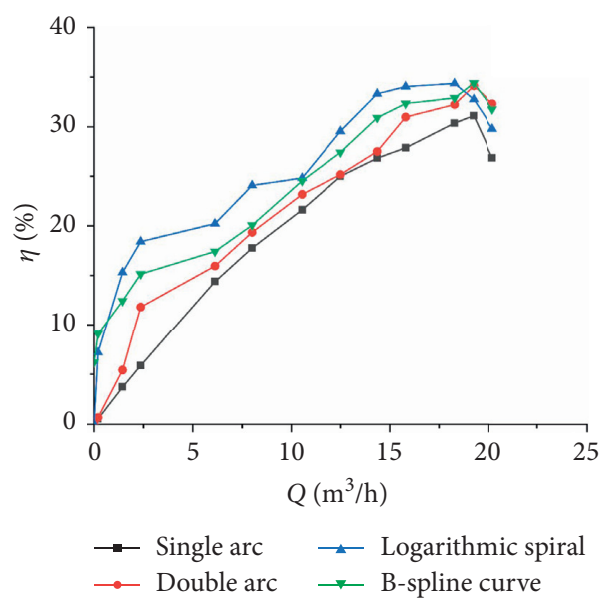

FIGURE 14: $Q-\eta$ curves four profiles. 


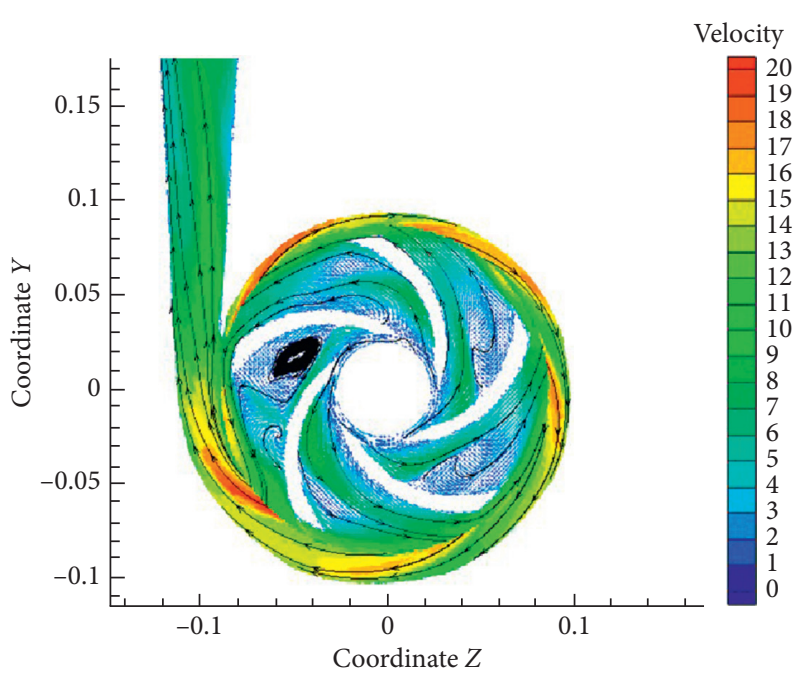

(a)

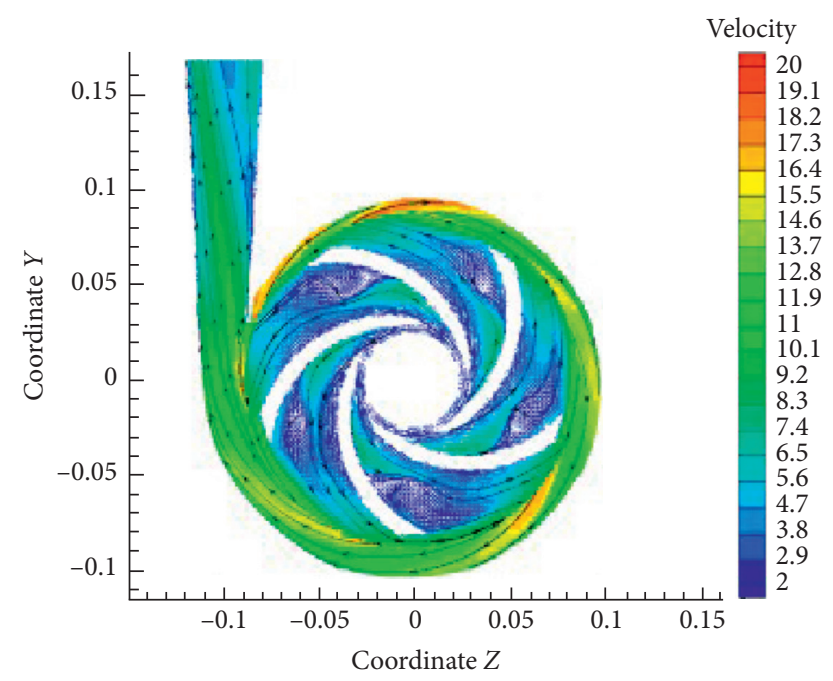

(c)

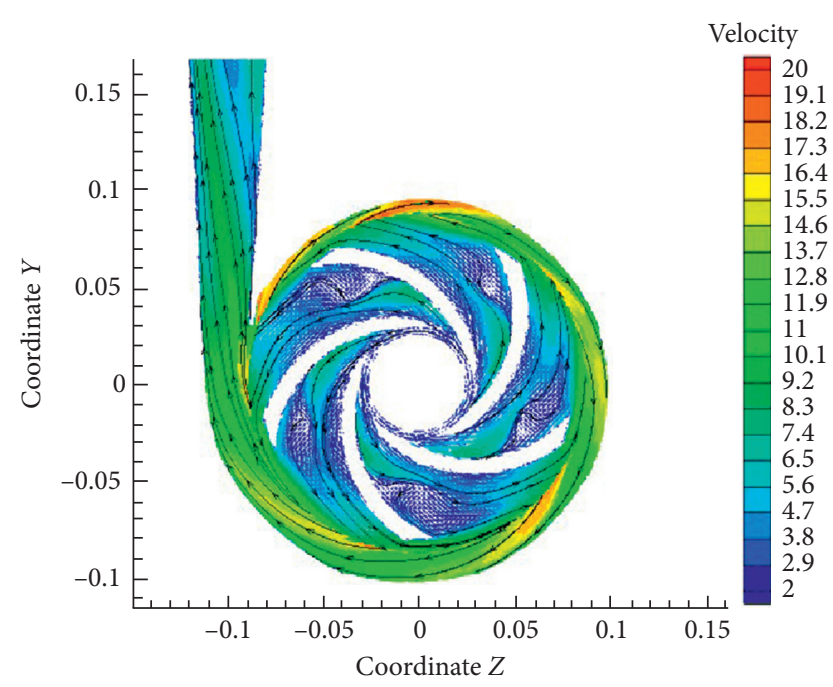

(b)

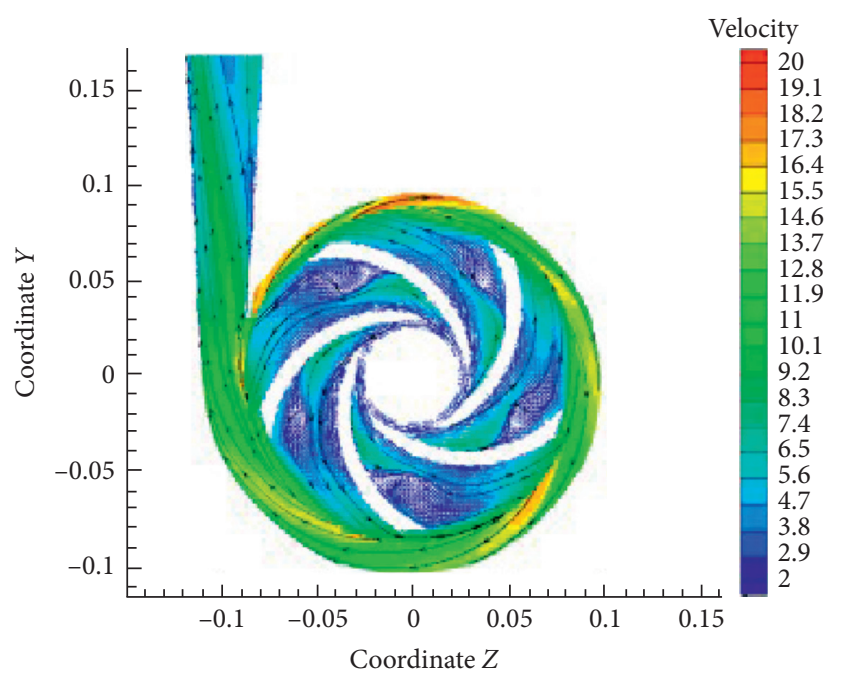

(d)

Figure 15: Contours of the velocity of the four impellers. (a) Single arc. (b) Double arc. (c) Logarithmic spiral. (d) B-spline curve.

\section{Optimization of the Logarithmic Spiral Method}

6.1. Objective Function. Based on the above analysis, it is shown that the logarithmic spiral method has the highest efficiency. To maximize the efficiency, the impeller inlet and outlet diameters $\left(D_{1}\right.$ and $\left.D_{2}\right)$ and impeller inlet and outlet installation angles $\left(\beta_{1}\right.$ and $\left.\beta_{2}\right)$ were taken as control variables and the total power loss and the minimum $\mathrm{NPSH}_{\mathrm{r}}$ of the pump were taken as the objective functions to optimize the impeller structure of the logarithmic spiral method.

6.1.1. Minimum $\mathrm{NPSH}_{r}$. The basic equation of $\mathrm{NPSH}_{\mathrm{r}}$ :

$$
\mathrm{NPSH}_{r}=\frac{v_{0}^{2}}{2 g}+\lambda \frac{\omega_{0}^{2}}{2 g} .
$$

Assuming that there is no prerotation at impeller inlet,

$$
\begin{aligned}
& v_{u o}=0, \\
& \omega_{0}^{2}=v_{0}^{2}+u_{0}^{2}, \\
& v_{0}=k_{2} \frac{4 Q}{\left(D_{1}^{2}-\mathrm{d}_{h}^{2}\right) \pi \eta_{v}}, \\
& u_{0}=k_{1} \frac{\pi n D_{j}}{60},
\end{aligned}
$$

where $k_{1}=0.876 ; k_{2}=0.91 ; D_{j}$-impeller inlet diameter $(\mathrm{m})$; $d_{h}$-impeller hub diameter $(m) ; \eta v=Q / Q t ; \lambda$-blade inlet pressure drop coefficient, $\lambda=0.15-0.3 ; v_{0}$-the absolute velocity of the slightly forward part of the blade inlet $(\mathrm{m} / \mathrm{s})$; and $\omega_{0}$-the relative velocity of the slightly forward part of the blade inlet $(\%)$. 

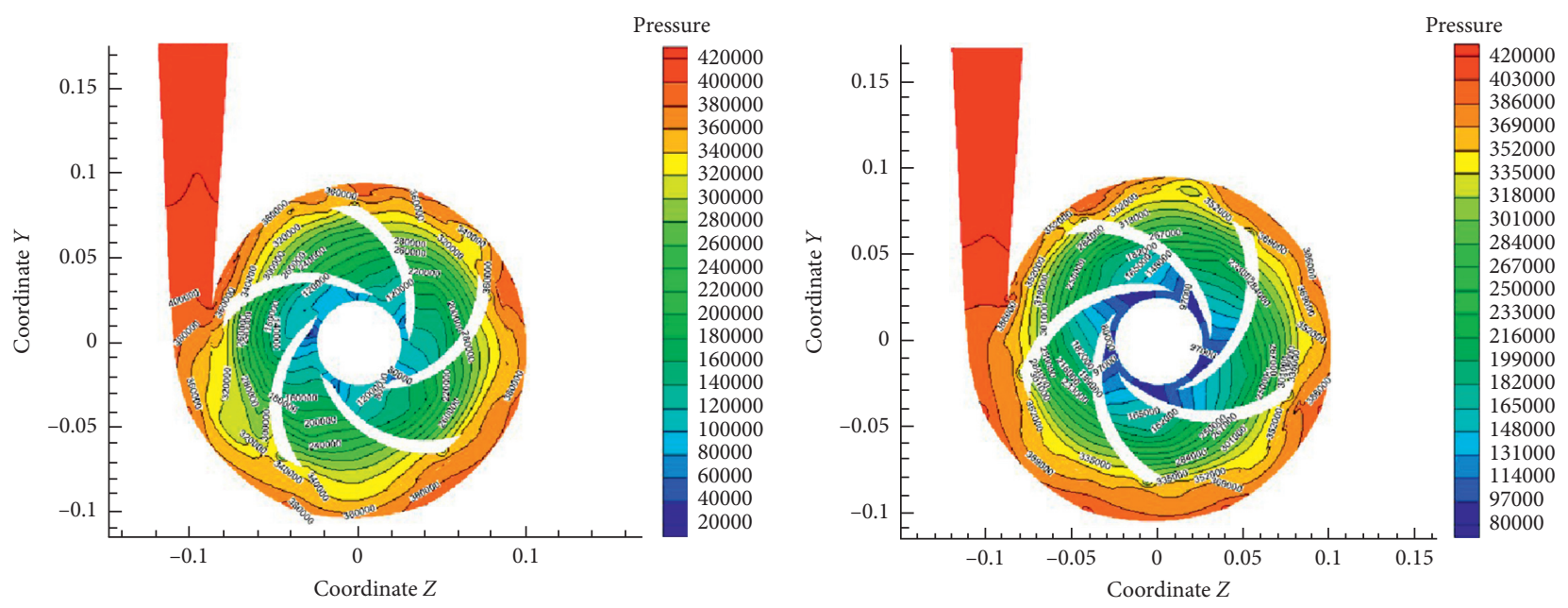

(a)

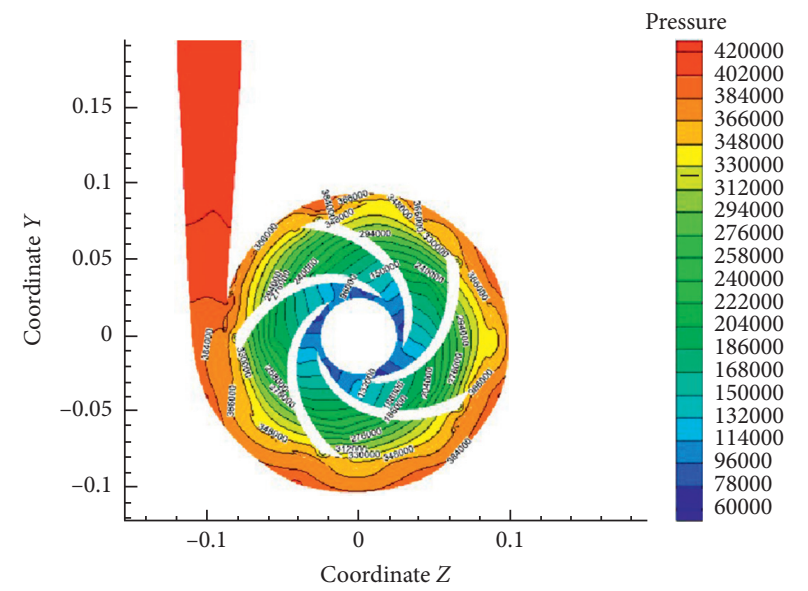

(c)

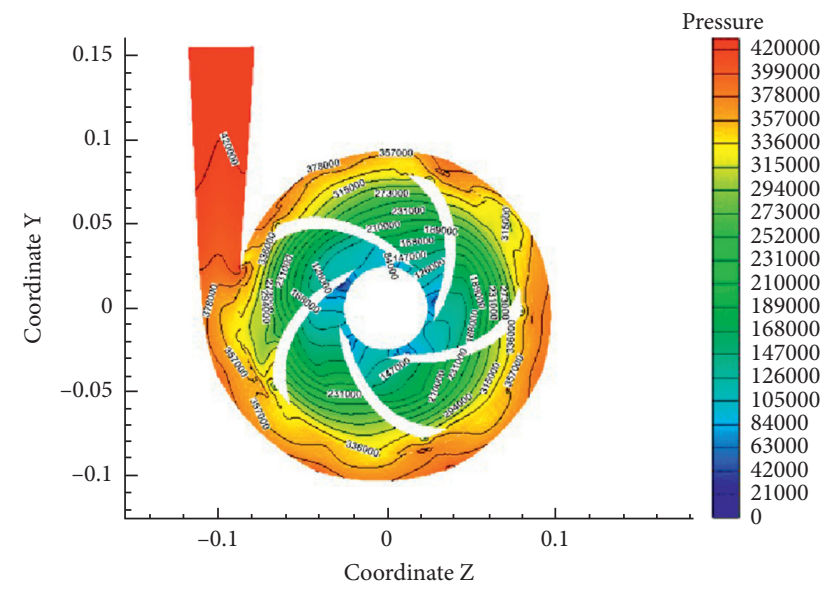

(d)

Figure 16: Contours of the pressure of the four impellers. (a) Single arc. (b) Double arc. (c) Logarithmic spiral. (d) B-spline curve.

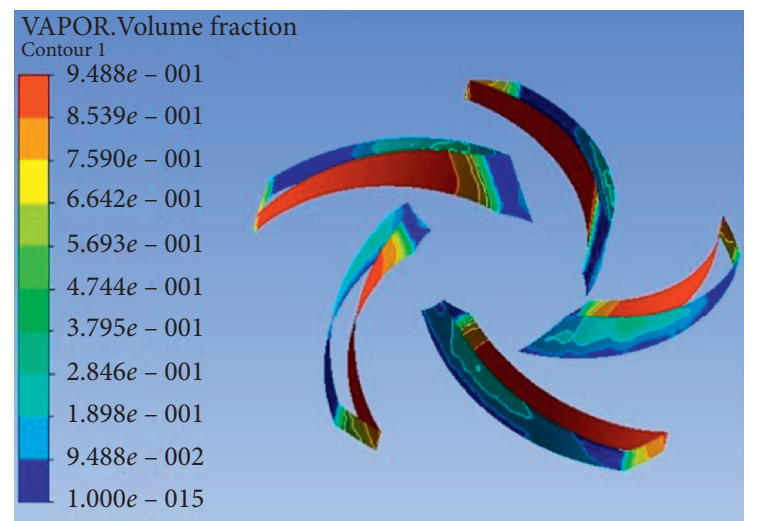

(a)

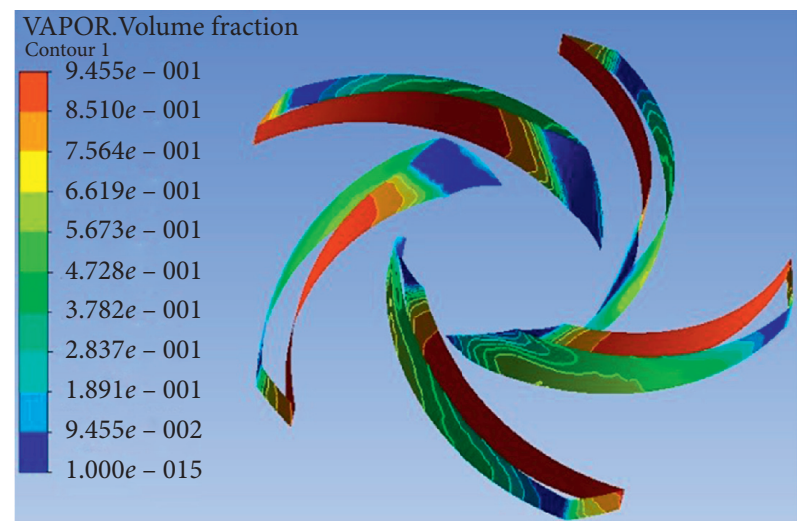

(b)

Figure 17: Continued. 


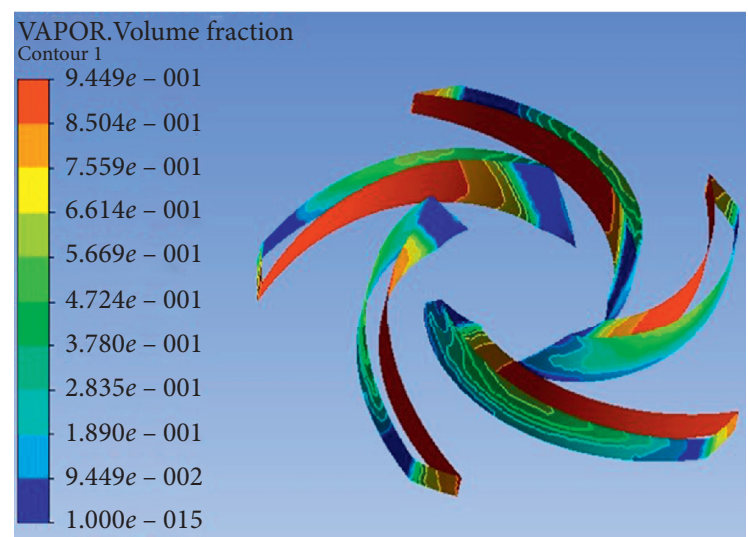

(c)

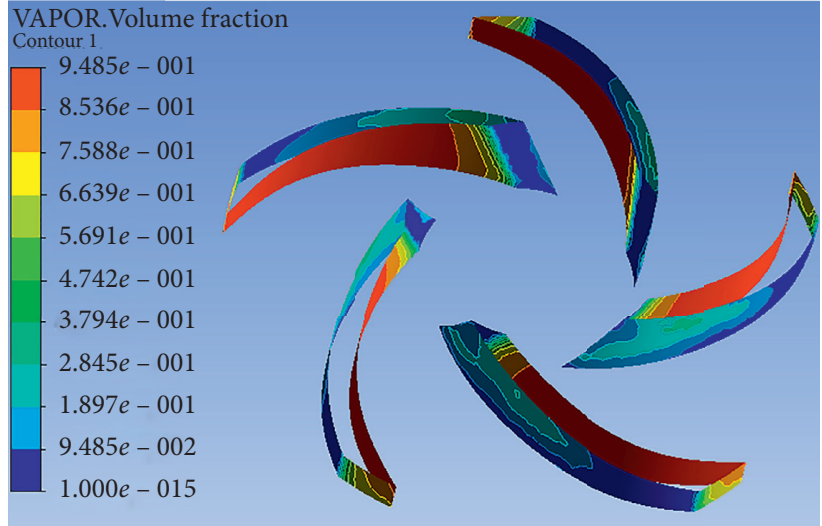

(d)

Figure 17: Vapor volume fraction distribution $\left(\mathrm{NPSH}_{\mathrm{r}}=1 \mathrm{~m}\right.$ ). (a) Single arc. (b) Double arc. (c) Logarithmic spiral. (d) B-spline curve.

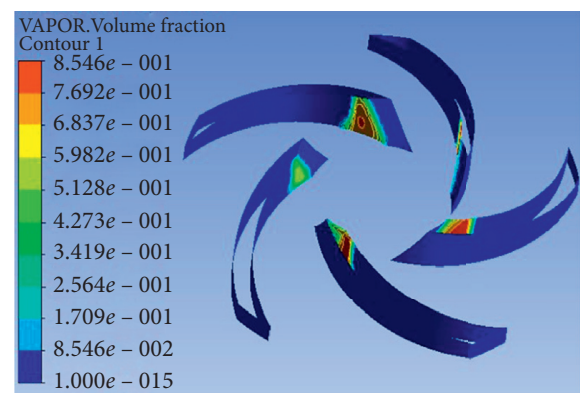

(a)

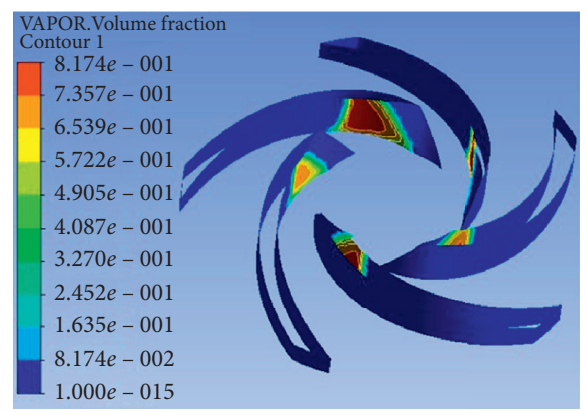

(c)

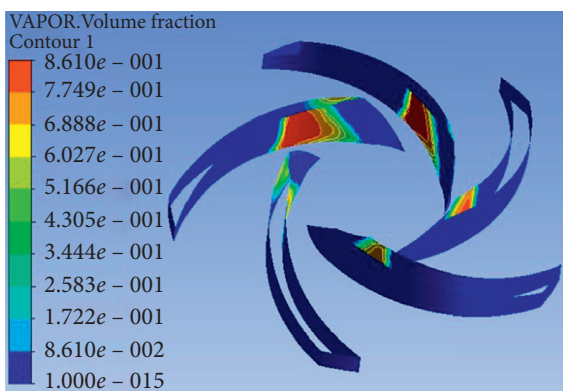

(b)

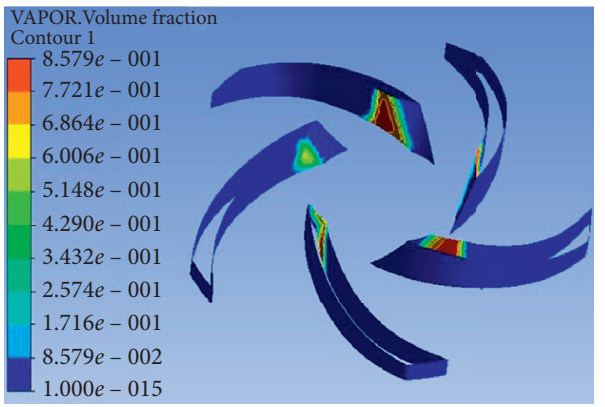

(d)

FIGURE 18: Vapor volume fraction distribution $\left(\mathrm{NPSH}_{\mathrm{r}}=2 \mathrm{~m}\right.$ ). (a) Single arc. (b) Double arc. (c) Logarithmic spiral. (d) B-spline curve.

TABLE 8: Performance parameters comparison of four methods.

\begin{tabular}{lcccc}
\hline Method & Single arc & Double arc & Logarithmic spiral & B-spline curve \\
\hline $\mathrm{H}(\mathrm{m})$ & 35.4435 & 35.4653 & 35.541 & 35.3835 \\
$\mathrm{P}(\mathrm{kW})$ & 3.50485 & 3.3662 & 3.30089 & 3.51129 \\
$\eta(\%)$ & 76.99 & 81.53 & 81.98 & 76.72 \\
\hline
\end{tabular}

Then,

$$
\mathrm{NPSH}_{r}=\frac{1}{2 g}(1+\lambda) \frac{k_{2}^{2} 4^{2} Q^{2}}{\left(D_{1}^{2}-d_{h}\right) \pi^{2} \eta_{v}^{2}}+\lambda \frac{k_{1} \pi^{2} n^{2} D_{j}^{2}}{60^{2} \times 2 g} \text {. }
$$

Therefore, the minimum objective function of $\mathrm{NPSH}_{\mathrm{r}}$ is $\min \left[f_{1}(x)=\mathrm{NPSH}_{r}\right]$.
6.1.2. Minimum Power Loss. The centrifugal pump losses mainly include volume, mechanical, and hydraulic losses. The volume loss accounts for a small proportion of the total loss, so the volume loss can be ignored. The optimization model is established with the mechanical loss and hydraulic loss. 


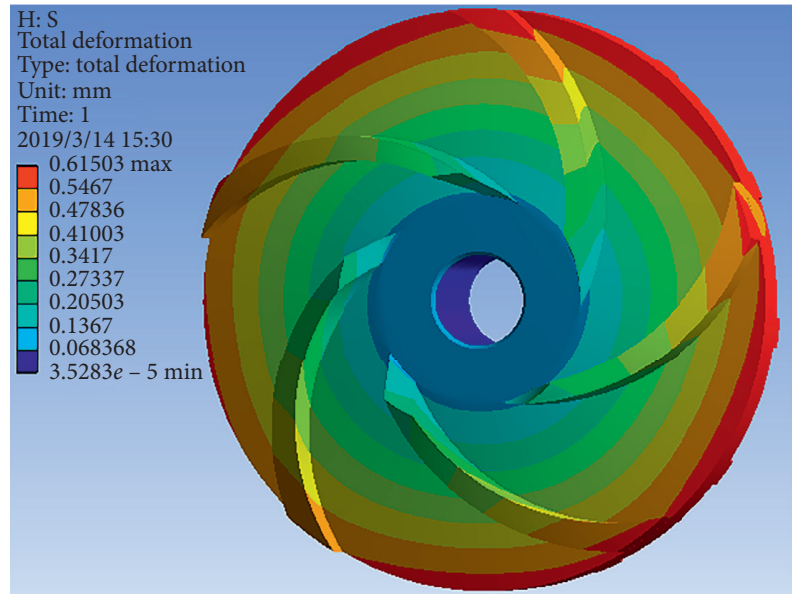

(a)

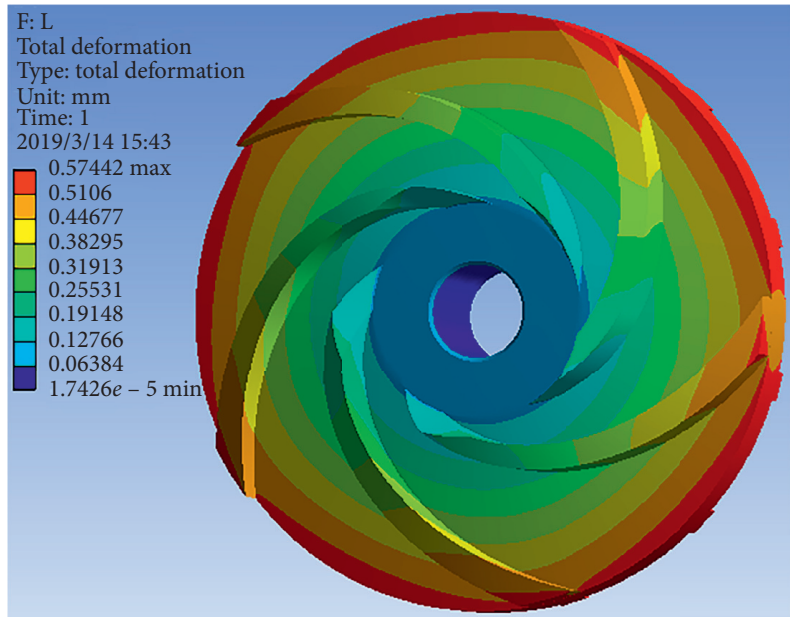

(c)

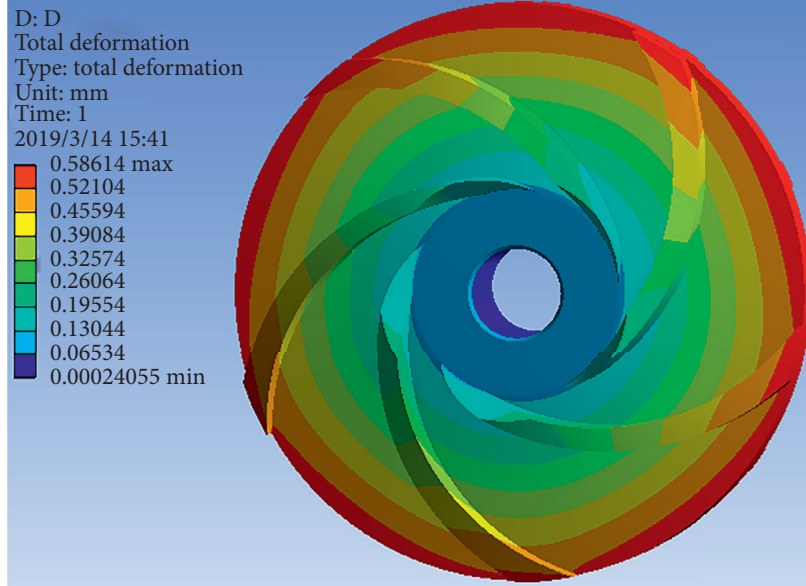

(b)

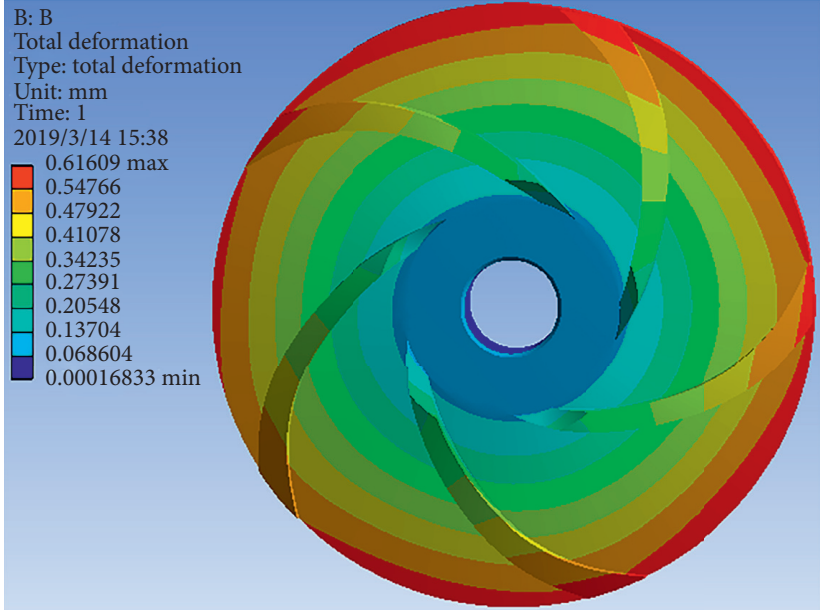

(d)

Figure 19: Total deformation of the impellers. (a) Single arc. (b) Double arc. (c) Logarithmic spiral. (d) B-spline curve.

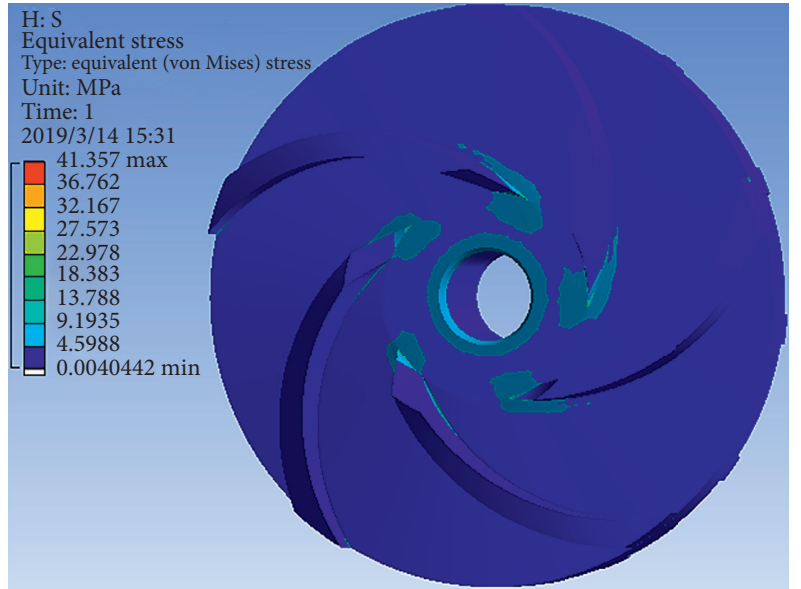

(a)

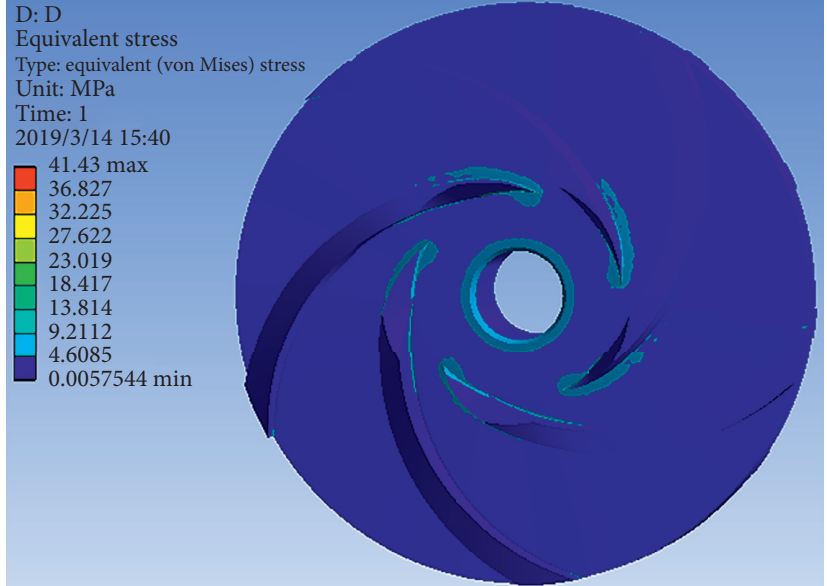

(b)

Figure 20: Continued. 


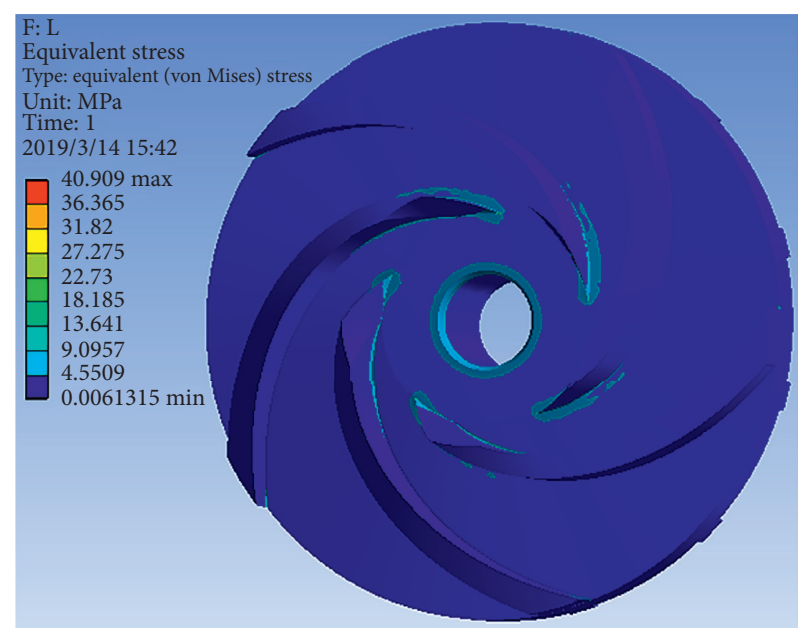

(c)

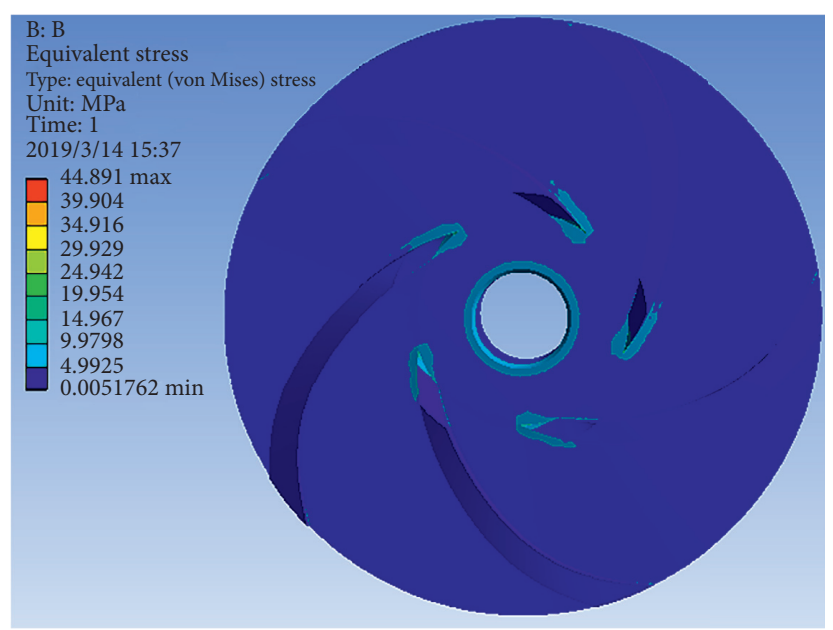

(d)

Figure 20: Equivalent stress of the impellers. (a) Single arc. (b) Double arc. (c) Logarithmic spiral. (d) B-spline curve.

$$
P=P_{m 1}+P_{m 2}
$$

where $P$-total loss power $(\mathrm{kW}) ; P_{m 1}$-hydraulic loss power $(\mathrm{kW})$; and $P_{m 2}-$ mechanical loss power $(\mathrm{kW})$.

$$
\begin{aligned}
& P_{m 1}=\frac{t_{1} \rho Q v_{2}^{2}}{2}, \\
& P_{m 2}=0.35 t_{2} \times 10^{-2} \rho \omega^{3} R_{2}^{5},
\end{aligned}
$$

where $t_{1}$-velocity energy loss coefficient in the pressurized water chamber, $t_{1}=0.15 \sim 0.25 ; t_{2}$-dimensionless disc friction coefficient, $t_{2}=0.8 \sim 1.0 ; \mathrm{v}_{2}$-the absolute velocity of impeller outlet $(\mathrm{m} / \mathrm{s})$; $\omega$-the rotational angular velocity of the shaft $(\%)$; and $R_{2}$-impeller radius $(\mathrm{m})$.

Assuming that there is no prerotation at impeller inlet, $u_{1}=0$. According to Stodola's equation,

$$
\begin{aligned}
H_{t} & =\frac{u_{2}}{g}\left(\sigma u_{2}-\frac{V_{m 2}}{\tan \beta_{2}}\right), \\
u_{2} & =\frac{n \pi R_{2}}{30} \\
\sigma & =1-\frac{\pi}{2} \sin \beta_{2}, \\
V_{m 2} & =\frac{2 Q_{t}}{b_{2} \psi_{2} R_{2} \pi} .
\end{aligned}
$$

Then,

$$
H_{t}=\frac{1}{g}\left[\left(\frac{n \pi R_{2}}{30}\right)^{2}\left(1-\frac{\pi \sin \beta_{2}}{Z}\right)-\frac{n Q_{t}}{60 b_{2} \psi_{2} \tan \beta_{2}}\right],
$$

where $u_{1}, u_{2}$-the circumferential velocity of inlet and outlet $(\mathrm{m} / \mathrm{s}) ; v_{u 1}, v_{u 2}$-the circumferential absolute velocity of inlet and outlet $(\mathrm{m} / \mathrm{s}) ; H_{t}$-theoretical head of the pump (m); $n$-rotational speed ( $\mathrm{rad} / \mathrm{s}) ; \psi_{2}$-crowding coefficient of impeller outlet, $\psi_{2}=0.842$; and $\sigma$-Stodola's slip coefficient.

Impeller outlet speed triangle:

$$
\begin{aligned}
v_{2}^{2} & =v_{m 2}^{2}+v_{u 2}^{2}, \\
v_{m 2} & =\frac{2 Q_{t}}{\pi R_{2} b_{2} \psi_{2}}, \\
v_{u 2} & =\frac{g H_{t}}{u_{2}} .
\end{aligned}
$$

Then,

$$
\begin{aligned}
P= & \frac{\left(1-\left(\pi \sin \beta_{2} / Z\right)\right)}{g H_{t}+\left(n Q_{t} / 60 b_{2} \psi_{2} \tan \beta_{2}\right)} \\
& \bullet\left\{\frac{t_{1} \rho Q}{2}\left[g^{2} H_{t}^{2}+\left(\frac{n Q_{t}}{60 b_{2} \psi_{2}}\right)^{2}\right]+\frac{1}{4 \times 60^{2}}\right. \\
& \left.\bullet\left[0.35 \times 10^{-2} t_{2} \rho(n \pi)^{2}\left(\frac{60 g H_{t}}{n \pi}\right)^{3}\left(1+\frac{n Q_{t}}{60 g H_{t} b_{2} \psi_{2}}\right)^{(3 / 2)}\right]\right\} .
\end{aligned}
$$

Therefore, the minimum objective function of $P$ is $\min \left[f_{2}\right.$ $(x)=P]$.

6.1.3. Unified Objective Function. The weighting coefficient transformation method is used to deal with the two objective functions. According to the actual situation, the power loss of the plastic centrifugal pump has a greater impact on the total efficiency of the pump than $\mathrm{NPSH}_{\mathrm{r}}$. Therefore, it is assumed that $\mathrm{NPSH}_{\mathrm{r}}$ accounts for $30 \%$ and the power loss accounts for $70 \%$ for optimization and the unified objective function is $\min \left[f(x)=0.3 P+0.7 \mathrm{NPSH}_{\mathrm{r}}\right]$.

6.2. Constraint Conditions. The constraint ranges of design variables were determined by combining the statistical 
TABLE 9: Comparison of optimization design variables.

\begin{tabular}{lcccc}
\hline Parameters & $D_{1}(\mathrm{~mm})$ & $D_{2}(\mathrm{~mm})$ & $\beta_{1}\left({ }^{\circ}\right)$ & $\beta_{2}\left(^{\circ}\right)$ \\
\hline Before optimization & 58 & 162 & 20 & 30 \\
After optimization & 58 & 162 & 17 & 31 \\
\hline
\end{tabular}

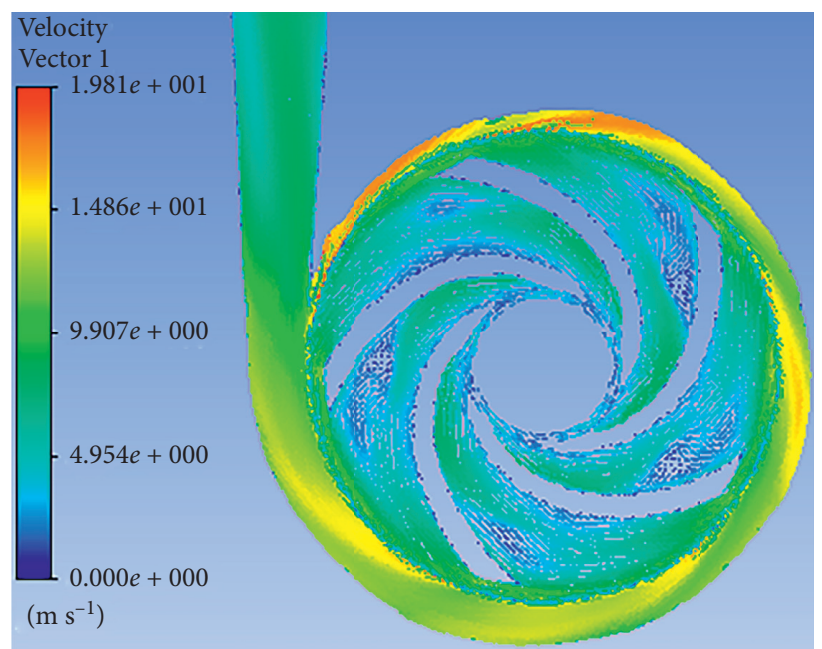

(a)

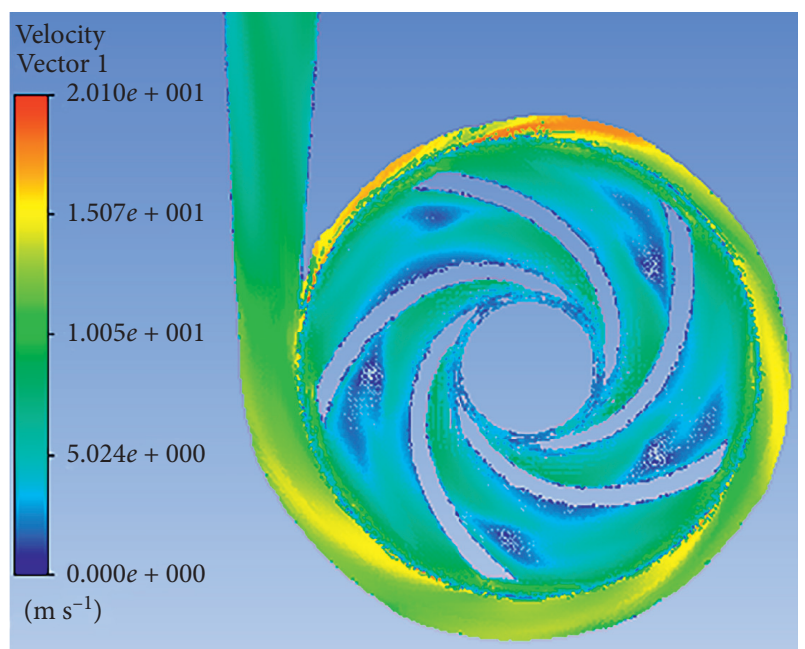

(b)

FIGURE 21: Optimization results.

formula of the velocity coefficient method with the actual excellent model pump. Then, we increased the constraint ranges appropriately.

Constraint formulas:

$$
\begin{aligned}
2 \sqrt[3]{\frac{Q}{n}} & <D_{1}<4 \sqrt[3]{\frac{Q}{n}}, \\
9.35\left(\frac{n_{s}}{100}\right)^{(1 / 2)} \sqrt[3]{\frac{Q}{n}} & <D_{2}<10.5\left(\frac{n_{s}}{100}\right)^{(1 / 2)} \sqrt[3]{\frac{Q}{n}}, \\
10^{\circ} & <\beta_{1}<30^{\circ}, \\
20^{\circ} & <\beta_{2}<40^{\circ} .
\end{aligned}
$$

6.3. Multiobjective Function Optimization. According to the creation of a multiobjective optimization program, the four parameters of impeller inlet and outlet diameters and impeller inlet and outlet installation angles were optimized. The final optimization results were that the impeller inlet and outlet diameters were $57.778 \mathrm{~mm}$ and $161.57 \mathrm{~mm}$ and the impeller inlet and outlet installation angles were $16.836^{\circ}$ and $30.68^{\circ}$. The optimization results were rounded and compared with those before optimization, and the design variables are shown in Table 9.

6.4. Simulation Comparison and Verification. The optimized parameters were used to remodel the impeller. Under the same working conditions, the internal flow field simulation was performed. The results after analysis are shown in
Figure 21. It can be seen that after optimization, the flow in the impeller was more sufficient. The efficiency was $83.66 \%$ after calculation, which was $1.68 \%$ higher than before. Therefore, the performance of the optimized impeller had been improved.

\section{Conclusions}

(1) According to the basic parameters of the centrifugal pump and the four different design methods of impeller profile, the shapes and sizes of several profiles were determined. Three-dimensional models were drawn by UG software. ANSYS-ICEM software was utilized to mesh the computational domains.

(2) According to the three-dimensional models drawn by four profile design methods, the impeller models were printed by $3 \mathrm{D}$ printing technology. The performance experiments of the plastic centrifugal pumps were carried out. The experimental results showed that the logarithm spiral method was the best and the single arc method was the worst.

(3) The analysis of numerical simulation was performed by FLUENT software. From the contours of velocity and pressure, the flow field in the impeller drawn by the logarithmic spiral method was significantly better. The maximum pressure values corresponding to the four methods were $437563 \mathrm{~Pa}, 441628 \mathrm{~Pa}$, $438368 \mathrm{~Pa}$, and $435518 \mathrm{~Pa}$. From the vapor volume fraction distribution, when $\mathrm{NPSH}_{\mathrm{r}}=1 \mathrm{~m}$ and $2 \mathrm{~m}$, 
the impeller drawn by the logarithmic spiral method was significantly better than the other three impellers. According to the calculation of performance parameters, it can be concluded that the impeller drawn by the logarithmic spiral method was the optimal impeller under the design condition.

(4) ANSYS-CFX software was used to complete the fluid-structure interaction analysis. The maximum total deformation of the impellers drawn by the four profile design methods was $0.61503 \mathrm{~mm}$, $0.58614 \mathrm{~mm}, 0.57442 \mathrm{~mm}$, and $0.61609 \mathrm{~mm}$, respectively. Deformation: B-spline curve method $>$ single arc method $>$ double arc method $>$ logarithmic spiral method. The maximum equivalent stress of the impellers drawn by the four profile design methods was $41.357 \mathrm{MPa}, \quad 41.43 \mathrm{MPa}, \quad 40.909 \mathrm{MPa}$, and 44.891 MPa, respectively. Equivalent stress: B-spline curve method $>$ double arc method $>$ single arc method $>$ logarithmic spiral method.

(5) Based on the analysis, the impeller drawn by the logarithmic spiral method had the highest efficiency. To maximize the efficiency, the impeller inlet and outlet diameters $\left(D_{1}\right.$ and $\left.D_{2}\right)$ and impeller inlet and outlet installation angles $\left(\beta_{1}\right.$ and $\left.\beta_{2}\right)$ were taken as control variables and the total power loss and the minimum $\mathrm{NPSH}_{\mathrm{r}}$ of the pump were taken as the objective functions. The final optimization results were that the impeller inlet and outlet diameters were $58 \mathrm{~mm}$ and $162 \mathrm{~mm}$ and the impeller inlet and outlet installation angles were $17^{\circ}$ and $31^{\circ}$. The hydraulic efficiency was increased by $1.68 \%$ after calculation, which indicated that the impeller structure had been improved.

\section{Abbreviations}

$D_{1}$ : Impeller inlet diameter, $\mathrm{mm}$

$D_{2}$ : Impeller outlet diameter, $\mathrm{mm}$

$\beta_{1}$ : Impeller inlet installation angle, ${ }^{\circ}$

$\beta_{2}$ : Impeller outlet installation angle,

$\rho: \quad$ Radius of curvature, $\mathrm{mm}$

$R_{1}$ : Impeller inlet radius, $\mathrm{mm}$

$R_{2}$ : Impeller outlet radius, $\mathrm{mm}$

$R_{f}$ : Radius of rotation of the point $F, \mathrm{~mm}$

$\beta_{f}$. Blade angle of point $\mathrm{F}$,

Z: Number of blades

$\beta$ : Impeller installation angle, ${ }^{\circ}$

$\psi$ : Wrap angle, ${ }^{\circ}$

$\theta$ : Variation of wrap angle $\psi$,

Q: $\quad$ Flow rate, $\mathrm{m}^{3} / \mathrm{h}$

$H$ : Pump head, $\mathrm{m}$

$n$ : $\quad$ Rotational speed, $r / \mathrm{min}$

$n_{\mathrm{s}}$ : Specific speed

$P_{t}$ : Shaft power, $\mathrm{kW}$

$D_{j}$ : Impeller inlet diameter, $\mathrm{m}$

$d_{h}$ : Impeller hub diameter, $\mathrm{m}$

$\lambda$ : $\quad$ Blade inlet pressure drop coefficient

$v_{0}$ : Absolute velocity of the slightly forward part of the blade inlet, $\mathrm{m} / \mathrm{s}$ $\omega_{0}$ : Relative velocity of the slightly forward part of the blade inlet, $\%$

$P: \quad$ Total loss power, $\mathrm{kW}$

$P_{m 1}$ : Hydraulic loss power, $\mathrm{kW}$

$P_{m 2}$ : Mechanical loss power, $\mathrm{kW}$

$t_{1}$ : Velocity energy loss coefficient in the pressurized water chamber

$t_{2}$ : Dimensionless disc friction coefficient

$v_{2}$ : Absolute velocity of impeller outlet, $\mathrm{m} / \mathrm{s}$

$u_{1}$ : Circumferential velocity of inlet, $\mathrm{m} / \mathrm{s}$

$u_{2}$ : Circumferential velocity of outlet, $\mathrm{m} / \mathrm{s}$

$v_{u 1}$ : Circumferential absolute velocity of inlet, $\mathrm{m} / \mathrm{s}$

$v_{u 2}$ : Circumferential absolute velocity of outlet, $\mathrm{m} / \mathrm{s}$

$H_{t}$ : Theoretical head of the pump, $\mathrm{m}$

$\psi_{2}$ : Crowding coefficient of impeller outlet

$\sigma: \quad$ Stodola's slip coefficient.

\section{Data Availability}

The data used to support the findings of this study are included within the article.

\section{Conflicts of Interest}

The authors declare that they have no conflicts of interest.

\section{Acknowledgments}

This work was supported by the University Synergy Innovation Program of Anhui Province (GXXT-2019-004), the Teaching Research Project of Anhui Education Department (2019jyxm0229), and the Natural Science Foundation of Anhui Province Education Department (KJ2017ZD12).

\section{References}

[1] M. Tan, Y. Lu, X. Wu, H. Liu, and X. Tian, "Investigation on performance of a centrifugal pump with multi-malfunction," Journal of Low Frequency Noise, Vibration and Active Control, Article ID 146134842094234, 2020.

[2] M. Liu, L. Tan, and S. Cao, "Theoretical model of energy performance prediction and BEP determination for centrifugal pump as turbine," Energy, vol. 172, pp. 712-732, 2019.

[3] X. Li, B. Chen, X. Luo, and Z. Zuchao, "Effects of flow pattern on hydraulic performance and energy conversion characterisation in a centrifugal pump," Renewable Energy, vol. 151, pp. 475-487, 2020.

[4] D. Wu, Y. Ren, J. Mou et al., "Unsteady flow and structural behaviors of centrifugal pump under cavitation conditions [J]," Chinese Journal of Mechanical Engineering, vol. 32, no. 01, pp. 127-141, 2019.

[5] X. Li, Z. Jiang, and Z. Zhu, "Entropy generation analysis for the cavitating head-drop characteristic of a centrifugal pump," Archive Proceedings of the Institution of Mechanical Engineers Part C Journal of Mechanical Engineering Science, vol. 203210, 2018 https://www.semanticscholar.org/author/Q.-Si/ 2164738https://www.semanticscholar.org/author/Y.-Li/ 47002268, Article ID 095440621775345.

[6] P. A. Kumar, R. J. Shruti, and T. Rajiv, "Prediction of flow blockages and impending cavitation in centrifugal pumps using 
Support Vector Machine (SVM) algorithms based on vibration measurements," Measurement, vol. 130, pp. 44-56, 2018.

[7] X. He, W. Jiao, C. Wang, and C. Weidong, "Influence of surface roughness on the pump performance based on computational fluid dynamics," IEEE Access, vol. 99, p. 1, 2019.

[8] H. S. Shim, K. Y. Kim, and Y. S. Choi, "Three-objective optimization of a centrifugal pump to reduce flow recirculation and cavitation," Journal of Fluids Engineering, vol. 140, no. 9, 14 pages, Article ID 091202, 2018.

[9] Y. Li, G. Feng, and X. Li, Z. Zuchao, An experimental study on the cavitation vibration characteristics of a centrifugal pump at normal flow rate," Journal of Mechanical Science and Technology, vol. 32, no. 10, pp. 4711-4720, 2018, https://www. researchgate.net/profile/Quiorui_Si.

[10] A. R. Al-Obaidi, "Investigation of effect of pump rotational speed on performance and detection of cavitation within a centrifugal pump using vibration analysis," Heliyon, vol. 5, no. 6, 2019.

[11] D. O. W. Dimar, V. D. S. Martijn, and N. P. Kruyt, "Prediction of the effect of impeller trimming on the hydraulic performance of low specific-speed centrifugal pumps," Journal of Fluids Engineering, vol. 140, no. 8, 2018.

[12] Y. Yuan, S. Yuan, and L. Tang, "Investigation on the effect of complex impeller on vibration characteristics for a high-speed centrifugal pump," Proceedings of the Institution of $\mathrm{Me}$ chanical Engineers Part A Journal of Power and Energy, vol. 234, no. 5, Article ID 095765091987831, 2019.

[13] B. Cui, C. Zhang, Y. Zhang, and Z. Zhu, "Influence of cutting angle of blade trailing edge on unsteady flow in a centrifugal pump under off-design conditions," Applied Sciences, vol. 10, no. 2, p. 580, 2020.

[14] Y. Song, Z. Yu, G. Shi et al., "Influence of impeller staggered arrangement on radial force and pressure fluctuation for a double-suction centrifugal pump," Advances in Mechanical Engineering, vol. 10, p. 6, 2018.

[15] J. M. Jin, K. J. Jung, Y. H. Kim, and Y.-J. Kim, "Effects of gap between impeller and volute tongue on a pressure fluctuation in double-suction pump," Journal of Mechanical Ence and Technology, pp. 1-7, 2020.

[16] D. C. Fu, F. J. Wang, P. J. Zhou et al., "Impact of impeller stagger angles on pressure fluctuation for a double-suction centrifugal pump," Chinese Journal of Mechanical Engineering, vol. 31, no. 1, p. 10, 2018.

[17] H. Yousefi, Y. Noorollahi, M. Tahani, R. Fahimi, and S. Saremian, "Numerical simulation for obtaining optimal impeller's blade parameters of a centrifugal pump for highviscosity fluid pumping," Sustainable Energy Technologies and Assessments, vol. 34, pp. 16-26, 2019.

[18] N. A. Mandhare, K. Karunamurthy, and S. Ismail, "Computational investigation of flow over nose cap of closed impeller of mixed flow centrifugal pump," Journal of Pressure Vessel Technology, vol. 142, no. 3, 2019.

[19] L. Dong, Y. Zhao, H. Liu et al., "The effect of front streamline wrapping angle variation in a super-low specific speed centrifugal pump," Journal of Mechanical Engineering Science, vol. 232, no. 23, Article ID 095440621877260, 2018.

[20] D. Zindani, A. K. Roy, and K. Kumar, "Design of mixed flow pump impeller blade using mean stream line theory and its analysis," Scientia Iranica, 2018.

[21] Y. Tao, S. Yuan, and J. Liu, T. Jianping, The influence of the blade thickness on the pressure pulsations in a ceramic centrifugal slurry pump with annular volute," Journal of
Power and Energy, vol. 231, no. a5, pp. 415-431, 2017, https:// www.researchgate.net/profile/Fan_Zhang410.

[22] R. Tao, R. Xiao, and Z. Wang, "Influence of blade leading-edge shape on cavitation in a centrifugal pump impeller," Energies, vol. 11, no. 10, p. 11, 2018.

[23] G. Peng, Q. Chen, L. Zhou, B. Pan, and Y. Zhu, "Effect of blade outlet angle on the flow field and preventing overload in a centrifugal pump," Micromachines, vol. 11, no. 9, p. 811, 2020.

[24] W. Yu-Qin and D. Ze-Wen, "Influence of blade number on flow-induced noise of centrifugal pump based on CFD/CA," Vacuum, vol. 172, Article ID 109058, 2019.

[25] X. Han, Y. Kang, J. Sheng et al., "Centrifugal pump impeller and volute shape optimization via combined NUMECA, genetic algorithm, and back propagation neural network," Structural and Multidiplinary Optimization, vol. 61, no. 3, 2019.

[26] R. H. Zhang, L. C. Yun, and J. Li, "Investigation on the effect of impeller slot jet on centrifugal pump performance," Journal of Hydrodynamics, vol. 31, no. 3, 2018.

[27] H. Wang, B. Long, C. Wang et al., "Effects of the impeller blade with a slot structure on the centrifugal pump performance," Energies, vol. 13, no. 7, 2020, https://www. researchgate.net/deref/http\%3A\%2F\%2Fdx.doi.org\%2F10. $3390 \% 2$ Fen 13071628.

[28] J. Li, L. Tang, and Y. Zhang, "The influence of blade angle on the performance of plastic centrifugal pump," Advances in Materials Science and Engineering, vol. 2020, Article ID 7205717, 20 pages, 2020.

[29] J. Hu, Y. Chen, Y. Wang, J. Cheng, and J. Zhao, "New method for drawing two arc cylindrical blade of centrifugal pump," Chemical Equipment Technology, vol. 37, no. 2, pp. 24-26, 2016.

[30] D. M. S. El-Gazzar and S. A. A. F. Hawash, "Optimizing centrifugal pump performance by different blade configuration patterns," American Journal of Mechanical and Industrial Engineering, vol. 3, no. 1, p. 1, 2018.

[31] J. Ming, L. Dong, H. Liu et al., "Research of variable angle spiral method for cylindrical blade profile in centrifugal pump," Water Resources and Power, vol. 35, no. 1, pp. 180183, 2017. 